OPEN ACCESS

Edited by:

John Hancock,

University of the West of England, United Kingdom

Reviewed by: Johannes Werner Stratmann, University of South Carolina, United States

Sorina Claudia Popescu, Mississippi State University, United States

*Correspondence: Daniel P. Matton

dp.matton@umontreal.ca

Specialty section: This article was submitted to Plant Physiology,

a section of the journal

Frontiers in Plant Science

Received: 03 May 2017

Accepted: 19 July 2017

Published: 08 August 2017

Citation:

Benhamman R, Bai F, Drory SB,

Loubert-Hudon A, Ellis B and Matton DP (2017) The Arabidopsis Mitogen-Activated Protein Kinase Kinase Kinase 20 (MKKK20) Acts Upstream of MKK3 and MPK18 in Two Separate Signaling Pathways Involved in Root Microtubule Functions. Front. Plant Sci. 8:1352. doi: 10.3389/fpls.2017.01352

\section{The Arabidopsis Mitogen-Activated Protein Kinase Kinase Kinase 20 (MKKK20) Acts Upstream of MKK3 and MPK18 in Two Separate Signaling Pathways Involved in Root Microtubule Functions}

\author{
Rachid Benhamman', Fangwen Bai', Samuel B. Drory', Audrey Loubert-Hudon', \\ Brian Ellis ${ }^{2}$ and Daniel P. Matton ${ }^{1 *}$ \\ ${ }^{1}$ Institut de Recherche en Biologie Végétale, Département de Sciences Biologiques, Université de Montréal, Montréal, \\ QC, Canada, ${ }^{2}$ Michael Smith Laboratories, University of British Columbia, Vancouver, BC, Canada
}

Mitogen-activated protein kinase (MAPK) signaling networks represent important means of signal transduction in plants and other eukaryotes, controlling intracellular signaling by linking perception of environmental or developmental cues to downstream targets. In the Arabidopsis MEKK subfamily, the MKKK19, 20, and 21 form a highly supported clade with the Solanaceous Fertilization-Related Kinases. In Arabidopsis, little is known about this group, except for MKKK20, which is involved in osmotic stress. Using a directed MKKK-MKK yeast two-hybrid (Y2H) screen, MKKK2O was found to interact only with MKK3, while a MKKK2O large-scale Y2H screen retrieved MPK18 as a direct interactant. In vitro phosphorylation assays showed that MKKK20 phosphorylates both MKK3 and MPK18. However, when all three kinases are combined, no synergistic effect is observed on MPK18 phosphorylation, suggesting a direct access to MPK18, consistent with the absence of interaction between MKK3 and MPK18 in protein-protein interaction assays. Since mpk18 mutant plants were previously shown to be defective in microtubulerelated functions, phenotypes of $m k k k 20$ single and $m k k k 20 / m p k 18$ double mutants were investigated to determine if MKKK20 acts upstream of MPK18. This was the case, as mkkk20 root length was shorter than WT in media containing microtubule-disrupting drugs as previously observed for mpk18 plants. Surprisingly, mkk3 plants were also similarly affected, suggesting the presence of two non-complementary pathways involved in Arabidopsis cortical microtubule function, the first including MKKK20, MKK3 and an unknown MPK; the second, a non-canonical MAPK cascade made of MKKK2O and MPK18 that bypasses the need for an MKK intermediate.

Keywords: MKKK20, MKK3, MPK18, Arabidopsis, roots, kinase cascade, microtubules 


\section{INTRODUCTION}

Microtubules are polymers of $\alpha$ - and $\beta$-tubulin heterodimers that help form the eukaryotic cytoskeleton. They are involved in many physiological processes such as development, morphogenesis, intracellular transport, cell division, and motility. Plant microtubule arrays differ from those in other eukaryotes in that they are dispersed and lack conspicuous organization (Dixit et al., 2006; Hamada, 2014). In addition, plant microtubules are organized into several distinct structures during the cell cycle (Ehrhardt and Shaw, 2006; Yamada and Goshima, 2017). During mitosis and after chromosomal segregation, plant cells build the bipolar phragmoplast array composed mainly of aligned microfilaments and highly dynamic microtubules. These microtubules form parallel arrays in the cell cortex, where they are organized into highly diverse patterns, relying on a variety of mechanisms for orientation, assembly, and function. In interphase cells, microtubules form parallel arrays in the cortex. The orientation of these arrays varies according to the cell type and stage of development. Cortical microtubules, for instance, are perpendicularly oriented during cell elongation, yet form parallel arrays during interphase (Lloyd and Chan, 2008; Chen et al., 2016).

Mitogen-activated protein kinases (MAPKs) were originally shown to phosphorylate the neuronal microtubule-associated protein, MAP2, after stimulation by insulin (Ray and Sturgill, 1987, 1988). Since then, MAPKs have been recognized as one of the most important cellular regulators of biological processes such as differentiation, proliferation, cell death, hormone signaling, osmotic stress, etc. (Colcombet and Hirt, 2008; Lu et al., 2015). Canonical MAPK cascades operate via successive phosphorylation steps starting with an upstream MAPK kinase kinase (MAPKKK or MKKK) that phosphorylates and activates a MAPK kinase (MAPKK or MKK) on one of two serine/threonine residues in a conserved $(\mathrm{S} / \mathrm{T})-\mathrm{X}_{5}$ $(\mathrm{S} / \mathrm{T})$ motif in plants and $(\mathrm{S} / \mathrm{T})-\mathrm{X}_{3}-(\mathrm{S} / \mathrm{T})$ in yeast and animals (Garrington and Johnson, 1999; Chang and Karin, 2001). The MKK then phosphorylates a MAPK (or MPK) by dual phosphorylation of the conserved-TXY-motif located in its activation loop. Typical MAPK substrates include transcription factors in addition to other cytoplasmic or nuclear proteins (Rodriguez et al., 2010). Activation of the upstream MAPKKK is more complex, and poorly understood in plants. Studies in yeast and animals show that MAPKKK activation can be mediated by MAPKKK kinases (Elion, 2000), G proteins (Fanger et al., 1997), and G protein-coupled receptors (Sugden and Clerk, 1997) or less frequently by the receiver domain of a two-component histidine kinase complex (Posas and Saito, 1997). The Arabidopsis thaliana genome encodes around 80 putative MAPKKKs (including 21 from the MEKK subfamily), 10 MAPKKs (MKKs), and 20 MAPKs (MPKs) (Ichimura and Group, 2002). The plant MAPKKKs can be further classified into two major groups: the MEKKs subgroup containing 21 kinases similar to animal MEKKs and yeast MAPKKKs, and the Raf-like kinases. Phylogenetically close sister clades such as the ZIK and MLK-like kinases are also considered as MAPKKKs although, so far, only the MEKKs are involved in MAPK cascades
(Rodriguez et al., 2010).These kinases have been implicated in a wide array of plant biological processes ranging from stress responses to development (Rodriguez et al., 2010). To date, however, only a limited number of complete MAPK cascades have been reported in plants, mainly in abiotic stress responses, plant-pathogen interactions and in plant development. For example, the first completely identified MAPK cascade was MEKK1-MKK4/MKK5-MPK3/MPK6, which acts upstream of two WRKY transcription factors, WRKY22/WRKY29. This cascade functions downstream from the FLS2 flagellin receptor kinase that ultimately enhance resistance and protects against multiple bacterial and fungal pathogens (Asai et al., 2002). In plant development, the $A$. thaliana MAPKKK YDA acts upstream of the MKK4/MKK5-MPK3/MPK6 signaling module, which functions in stomatal patterning and inflorescence development (Wang et al., 2007; Meng et al., 2012). In biotic and abiotic stress responses, the Nicotiana benthamiana MAPK cascade NPK1-MEK1-Ntf6 is involved in tobacco mosaic virus (TMV) resistance (Jin et al., 2002; Liu et al., 2004), while in A. thaliana, the MEKK1-MKK2-MPK4/MPK6 cascade mediates cold and salt stress responses (Teige et al., 2004), and the MEKK1MKK1/MKK2-MPK4 cascade functions as a negative regulator in innate immune responses (Gao et al., 2008). More recently, some ABA-regulated abiotic stress genes where also shown to depend on the MAPKKK17/18-MKK3-MPK1/2/7/14 cascade (Danquah et al., 2015).

The role of MAPK signaling in regulating microtubule functions has been widely documented in animals (Hoshi et al., 1992; Mandelkow et al., 1995; Verlhac et al., 1996; Terret et al., 2003; Zhao and Chen, 2006; Liu et al., 2007; Sun et al., 2008). Meanwhile, the involvement of MAPK-signaling in the regulation of plant microtubule functions has begun to emerge. In Arabidopsis, inhibition of protein tyrosine kinases and tyrosine phosphatases was reported to affect the dynamics and organization of cortical microtubules (Yemets et al., 2008). AtMPK4 and AtMPK6 were also shown to be necessary for cell division and localize to the phragmoplast during cytokinesis (Beck et al., 2011; Komis et al., 2011). Phosphorylation of the tobacco microtubule-associated protein MAP65-1 by the MAPK NRK1/NTF6 down-regulates the microtubule-bundling activity of NtMAP65-1 and positively regulates expansion of the phragmoplast (Sasabe et al., 2006). In addition, the NtMAP65-1 Arabidopsis ortholog, AtMAP65-1, has been shown to bind microtubule bundles specifically during interphase, anaphase, and telophase. When ectopically expressed in tobacco cells, a non-phosphorylatable AtMAP65-1 version affects mitotic division (Smertenko et al., 2006).

Arabidopsis MKKK20 participates in the osmotic stress response through its regulation of MPK6 (Kim et al., 2012), and was shown to interact with calmodulins (CaM) and CaM-like proteins (CML) in protein array assays (Popescu et al., 2007). Recently, insertional mutants of MKKK20 showed insensitivity to $\mathrm{ABA}$ in terms of root growth and stomatal response. In this context, MKKK20 was demonstrated to modulates abscisic acid responses acting upstream of MKK5 and MPK6 (Li et al., 2017). Arabidopsis MAPKKs have been classified into four groups, A-D (Soyano et al., 2003; Teige et al., 2004; Dai 
et al., 2006), with AtMKK3 belonging to group B, a singlemember clade characterized by the presence of a C-terminal NTF2 domain known to promote nuclear import of cargo proteins (Steggerda and Paschal, 2002). This feature could confer to MKK3 an important and singular rule among all other AtMKKs (Colcombet et al., 2016). MKK3 participates in pathogen signaling and is required for regulation during dark-light transition (Doczi et al., 2007; Lee, 2015). Arabidopsis root growth inhibition by jasmonate is negatively regulated by the MKK3/MPK6 cascade (Takahashi et al., 2007). This cascade, along with MYC2, is involved in blue light-mediated seedling development in Arabidopsis (Sethi et al., 2014). MKK3 also participates in an abscisic acid-activated MAPK cascade (Danquah et al., 2015). Recently, two MKK3 orthologs have been found to regulate seed dormancy in barley (Hordeum vulgare L.) and bread wheat (Triticum aestivum L.) (Nakamura et al., 2016; Torada et al., 2016). MAPKs are also divided into four groups (Ichimura and Group, 2002). AtMPK18 belongs to group $\mathrm{D}$, whose members harbor a-TDY-motif in their activation loop whereas the three other groups have aTEY-signature. AtMPK18 had been reported to interact with the phosphatase propyzamide hypersensitive 1 (PHS1) and is involved in microtubule functions (Walia et al., 2009).

Here we show that Arabidopsis MKKK20 physically interacts with both MKK3 and MPK18 and phosphorylates these kinases in vitro. Surprisingly, phosphorylated MKK3 did not increase MPK18 phosphorylation status when the three kinases were put together. Previous analysis showed that MPK18 is involved in microtubule-related functions in Arabidopsis (Walia et al., 2009). When tested in the presence of microtubule depolymerizing drugs, $m k k k 20$ and $m k k 3$ mutant plants were found to have shorter roots than wild type, resembling the $m p k 18$ behavior. This, combined with the analysis of $m k k k 20 / m p k 18$ and $m k k 3 / m p k 18$ double mutants suggests that MKKK20 modulates cortical microtubule functions through two independent MAPK signaling cascades, including a non-canonical pathway that bypasses the need for an intermediary MKK.

\section{MATERIALS AND METHODS}

\section{Plant Materials, Growth conditions, and Inhibitor Treatments}

Arabidopsis wild type (Col-0 accession), MKKK20 (SALK_021755 and SALK_124398), MPK18 (SALK_069399), and MKK3 (SALK_051970) T-DNA mutants were obtained from TAIR $^{1}$ (for T-DNA line details, see Supplementary Table S1). Seeds were grown in growth cabinets at $21^{\circ} \mathrm{C}$ with a light/dark cycle of $16 \mathrm{~h} / 8 \mathrm{~h}$ photoperiod. Primers used to screen for homozygous lines are listed in Supplementary Table S2. For root growth assays (elongation rate and skewing angles), seeds were grown aseptically on Hoagland medium solidified with 1.2\% agar. For oryzalin (Sigma-Aldrich) treatments, small volumes of a concentrated stock solution in DMSO were added to the molten agar; controls received the same amount of DMSO. Seeds

${ }^{1}$ http://www.arabidopsis.org sown on agar plates with or without oryzalin were kept for at least 7 days and placed vertically in a growth cabinet $\left(21^{\circ} \mathrm{C}\right.$, light/dark cycle of $16 \mathrm{~h} / 8 \mathrm{~h}$ and $120 \mu \mathrm{mol} \mathrm{m}^{-2} \mathrm{~s}^{-1}$ ).

\section{Yeast Two-Hybrid Screening}

For large-scale yeast two-hybrid (Y2H) screening, a normalized library made from 11 Arabidopsis tissues was used (Mate and Plate Library - Universal Arabidopsis Clontech $\left.{ }^{\circledR}\right)$. The library was transformed into yeast strain Y187 (MAT $\alpha)$, which can be readily mated to a MATa GAL4 reporter strain. The Matchmaker Gold Yeast Two-Hybrid System $\left(\right.$ Clontech $^{\circledR}$ ) was then used to screen the library. The MKKK20 cDNA bait was cloned into the pGBKT7 vector (GAL4 DNA-BD) and transformed into the $\mathrm{Y} 2 \mathrm{H}$ Gold yeast strain $\left(\right.$ Clontech $\left.^{\circledR}\right)$. Mating of the two sexually different strains was carried out at $30^{\circ} \mathrm{C}$ for $24 \mathrm{~h}$ and the resulting zygotes were plated directly on high stringency SD growth medium (-Leu/-Trp/-Ade/-His) supplemented with $40 \mu \mathrm{g} / \mathrm{ml} \mathrm{X}-\alpha-\mathrm{Gal}$ and $125 \mathrm{ng} / \mathrm{ml}$ Aureobasidin A. DNA from blue yeast colonies that survived this stringent selection was extracted and sequenced using the pGADT7-T 5AD primers. For the directed pairwise $\mathrm{Y} 2 \mathrm{H}$ screen, the ProQuest ${ }^{\mathrm{TM}}$ Twohybrid system from Invitrogen was used. All kinases were cloned and sequence-verified before being transferred into Gatewaycompatible destination vectors to generate the bait vector MKKK20 (in pDEST32) as the GAL4 DNA-binding domain (DBD) and the prey vectors AtMKK1-10 (in pDEST22) as the GAL4-activating domain (AD) and introduced pairwise into the yeast strain MaV203. Controls provided were used according to the manufacturer's instructions. Interaction strength for HIS3 and URA3 activation assays were scored by visual comparison to the controls.

\section{Promoter-GUS Expression and Microscopic Observations}

For GUS expression, a $1.5-\mathrm{kb}$ promoter region upstream of the MKKK20 coding sequence was cloned into the pMDC162 Gateway $^{\mathrm{TM}}$ vector harboring the $\beta$-glucuronidase gene to generate an N-terminal fusion reporter gene (Curtis and Grossniklaus, 2003). Primers are listed in Supplementary Table S3. The recombinant plasmid was then transformed into Agrobacterium tumefaciens C56C1 strain and used to transform wild type Arabidopsis (Col-0 accession) plants by the floral dipping method as described previously (Zhang et al., 2006). Seeds from M1 transformed plants were collected and grown in MS media containing $15 \mu \mathrm{g} / \mathrm{ml}$ hygromycin B for selection as described (Harrison et al., 2006). The M1 generation was analyzed for GUS gene expression and the true transformants (strongly growing seedling with well-developed hypocotyls) were grown on to generate an M2 generation. GUS staining was conducted as described before (Weigel and Glazebrook, 2002). Freshly harvested tissues from independent plant lines were collected and kept in $80 \%$ acetone before performing the $\beta$-glucuronidase assays in $100 \mathrm{mM}$ potassium phosphate buffer, $\mathrm{pH} 7,0.1 \%$ Triton X-100, $5 \mathrm{mM} \mathrm{K} \mathrm{K}_{3} \mathrm{Fe}(\mathrm{CN})_{6}$ and $5 \mathrm{mM} \mathrm{K} \mathrm{K}_{4} \mathrm{Fe}(\mathrm{CN})_{6}$. Tissues were then incubated in $2 \mathrm{mM}$ $\mathrm{X}$-Gluc at $37^{\circ} \mathrm{C}$ for $4 \mathrm{~h}$. The plant material was then cleared 
with increasing ethanol concentrations from 20 to $70 \%$, for $30 \mathrm{~min}$ each. Observations were performed using a Discovery V12 stereomicroscope or a Zeiss Axio Imager 1 microscope (under bright or dark field) and images were captured using an AxiocamHRc camera (Zeiss, Canada). Clearing of flowers and seedlings was performed by incubating tissues in 100\% ethanol for $1 \mathrm{~h}$ before transferring them to a methyl salicylate/EtOH solution with increasing ratios (1:3, 1:1, and 3:1) of methyl salicylate for $30 \mathrm{~min}$ each. The tissues were subsequently kept in $100 \%$ methyl salicylate (Sigma-Aldrich) at $4^{\circ} \mathrm{C}$ for no more than $24 \mathrm{~h}$ to avoid discoloration. The slides were mounted with $100 \%$ methyl salicylate and the observations were performed using a Zeiss Axio Imager 1 microscope under bright field.

\section{RNA Isolation for RT-PCR}

For RT-PCR, total RNA from various plant tissues was isolated using the TRIzol ${ }^{\circledR}$ RNA isolation reagent (Life Technologies) according to the manufacturer's instructions. Reverse transcription was performed using a first-strand cDNA synthesis M-MLV RT kit (Invitrogen). RT-PCR was conducted with gene-specific primers (Supplementary Table S3).

\section{GFP and Bimolecular Fluorescence Complementation Assays}

$M K K K 20, M K K 3$, and MPK18 full-length cDNAs were PCRamplified, cloned into the Gateway entry vector $\mathrm{pDONR}^{\mathrm{TM}} / \mathrm{Zeo}$ (Invitrogen) and sub-cloned into pMCD83 to generate an $\mathrm{N}$-terminal fusion with the GFP marker, or into the plant bimolecular fluorescence complementation (BiFC) vectors pUCSPYCE or pUC-SPYNE (Walter et al., 2004). All GFP and BiFC constructs were sequence-verified and prepared for transient transformation of onion epidermal cells by microparticle bombardment using a Bio-Rad PDS-1000/He bombardment system as described previously (Germain et al., 2008). The Arabidopsis bZIP63 transcription factor was used as positive control in BiFC assays (Walter et al., 2004).

\section{In Vitro Kinase Assays}

$M K K K 20, M K K K 20-K D$ (kinase dead), and MPK18 were expressed as His-tag fusion proteins in the pQLinHD (Addgene $\left.^{\circledR}\right)^{2}$ and $M K K 3$ was expressed as a His-GST-tag in the pDEST-565 vector $\left(\text { Addgene }^{\circledR}\right)^{3}$ using recombinant modified primers (see Supplementary Table S4). Plasmids were transformed in the Rosetta-gami Escherichia coli strain. MKKK20-KD was generated by replacing the conserved lysine $(\mathrm{K})$ in the kinase ATP-binding loop by a methionine (M). Bacterial cultures in LB media were induced with $0.1 \mathrm{mM}$ isopropyl-1-thio- $\beta$-D-galactopyranoside (IPTG) after reaching an $\mathrm{OD}_{600}$ absorbance of 0.5 and incubated at $37^{\circ} \mathrm{C}$ for an additional $3 \mathrm{~h}$ (except for MPK $18 ; 25^{\circ} \mathrm{C}$ overnight). Bacterial cells were pelleted at 10,000 rpm for $10 \mathrm{~min}$ and purified under denaturing conditions by re-suspending bacteria in $10 \mathrm{ml}$ lysis buffer $\left(100 \mathrm{mM} \mathrm{NaH} \mathrm{PO}_{4}, 10 \mathrm{mM}\right.$ Tris-Cl, $8 \mathrm{M}$ urea, $1 \mathrm{mM}$ PMSF, pH 8.0) per $100 \mathrm{ml}$. Bacterial cells were disrupted (twice)

${ }^{2}$ http://www.addgene.org/13668/

${ }^{3} \mathrm{http}: / /$ www.addgene.org/11520/ using a French pressure cell press at 950 psi. The resulting mixture was centrifuged at $10,000 \mathrm{rpm}$ for $10 \mathrm{~min}$ and the supernatant collected. Recombinant proteins were purified on HisTrap Ni columns using an ÄKTA Avant FPLC (GE Healthcare). For all kinase assay combinations, $1 \mu \mathrm{g}$ of each His-kinase was incubated for $30 \mathrm{~min}$ in $30 \mu \mathrm{l}$ kinase reaction buffer containing (50 mM Tris- $\mathrm{HCl}, \mathrm{pH}$ 7.5, $1 \mathrm{mM}$ DTT, $10 \mathrm{mM}$ $\mathrm{MgCl}_{2}, 10 \mathrm{mM} \mathrm{MnCl} 2,50 \mathrm{mM}$ ATP, and $0.037 \mathrm{MBq}\left[\gamma^{32} \mathrm{P}\right]$ ATP. Five micrograms of myelin basic protein (MBP) was added when indicated and enzymatic reactions were stopped by adding SDS sample buffer and heating for $4 \mathrm{~min}$ at $95^{\circ} \mathrm{C}$. Assays were then fractionated in an SDS-PAGE gel, stained by Coomassie Brilliant Blue and autoradiographed using a Typhoon Trio phosphorimager (GE Healthcare).

\section{Immunoblotting}

Proteins were separated on SDS/PAGE (12\% gel) and subsequently blotted onto a nitrocellulose membrane (Millipore $0.2 \mu \mathrm{M})$ and blocked in TBS containing 3\% dried non-fat skimmed milk powder, pH 7.4 solution for $2 \mathrm{~h}$. An anti-p-ERK antibody (phospho-ERK; Cell Signaling Technology) was used as first antibody and the HRP conjugated Goat anti-Rabbit IgG $(\mathrm{H}+\mathrm{L})$ secondary antibody (Thermo Fisher Scientific) as the second antibody.

\section{Complementation Test and Transgenic Transformation}

$M K K K 20$ and MKK3 cDNAs were PCR-generated using modified primers (Supplementary Table S5) that included a 6x-His tag addition to the protein C-terminal region and cloned in the $\mathrm{pDONR}^{\mathrm{TM}} / \mathrm{Zeo}$ vector (Invitrogen). The constructs were then transferred into the Gateway ${ }^{\circledR}$ binary vector pMDC32 (Curtis and Grossniklaus, 2003) to produce the p35S::MKKK20-6xHis and $p 35 S:: M K K 3-6 x H i$ s vectors. These constructs were used to complement $m k k k 20-1$ and $m k k 3$ mutant lines, respectively, using the floral dip method as described previously (Zhang et al., 2006). Positively transformed lines were selected using the abovementioned protocol (Harrison et al., 2006) and confirmed by western blotting using an anti-His antibody (Figure 6).

\section{RESULTS}

\section{MKKK20 Yeast-Two Hybrid Interactome}

Two Y2H screens were performed to identify possible MKKK20 interacting proteins and candidate substrates. First, a global $\mathrm{Y} 2 \mathrm{H}$ screen was performed using MKKK20 as bait against a normalized $A$. thaliana cDNA library (prey library) made from 11 tissues, including etiolated seedlings, seedlings with roots, open flowers, flower buds from different stages, pollen, siliques from all stages, stems and leaves. A two-step screen was performed. After mating, diploid yeast cells were selected based on their ability to grow on a -Leu/-Trp media that also contained Aureobasidine A $(\mathrm{AbA})$, an antibiotic toxic to yeast (AUR1-C gene reporter) and $\mathrm{X}-\alpha-\mathrm{Gal}$ (MEL1 gene reporter). Both reporters are activated in response to two-hybrid interactions. This led to the isolation of 
422 blue colonies. These colonies were then grown on a medium that used the four available reporters simultaneously (HIS3, ADE2, AUR1-C, MEL1). This further decreased the number of MKKK20 putative interactants to 66 non-redundant candidates. Interestingly, gene ontology analysis revealed that the GO term signaling (GO:0023052) counted for a third of the MKKK20 interacting proteins (Supplementary Table S6; S6.1 Process: biological process annotation level 2). These included seven protein kinases (five RLKs and one RLCK), one ARM-repeat kinase and a MAPK, the MPK18. Two protein phosphatases and two kinase binding protein were also retrieved. Also amongst the most represented categories, 10 are involved in cytoskeletal and cell wall functions and eight were transcription factors.

\section{MKKK20 Interacts Directly with MKK3 and MPK18}

In a canonical MAPK cascade, sequential phosphorylation and activation events activate the kinase members of the module. Thus, the upstream MKKK phosphorylates and activates the MKK, which in turn phosphorylates and activates the MPK. The absence of a MKK interactor in our MKKK20 global Y2H screen prompted us to screen all 10 Arabidopsis MKKs against MKKK20. In a directed pairwise $\mathrm{Y} 2 \mathrm{H}$ screen, only MKK3 was found to strongly interact with MKKK20 under stringent conditions (Figures 1A-C). Although MKKK20 physically interacted with MPK18 in the previous $\mathrm{Y} 2 \mathrm{H}$ systems, MKK3 might also interact with MPK18, as would be expected in a canonical MAPK cascade. However, the pairwise $\mathrm{Y} 2 \mathrm{H}$ interaction between MKK3 and MPK18 was much weaker than that detected between MKKK20 and MKK3 (Figure 1E). To confirm the physical association observed in the $\mathrm{Y} 2 \mathrm{H}$ assays between MKKK20, MKK3, and MPK18, BiFC assays were performed in onion leaf epidermal cells. A clear YFP signal was detected in both the nucleus and the cytoplasm when MKKK20 and MKK3 were bombarded together (Figures 2A,B), as well as for MKKK20 and MPK18 (Figures 2C,D). However, no signal was detected with the MKK3-MPK18 BiFC assay (Figures 2E,F), consistent with the interaction results obtained from the $\mathrm{Y} 2 \mathrm{H}$ screen.

\section{Expression Pattern of MKKK20, MKK3, and MPK18}

Semi-quantitative RT-PCR analyses from various Arabidopsis tissues were conducted to determine the extent of co-expression of $M K K K 20, M K K 3$, and $M P K 18$. Supplementary Figure S1 shows that all three kinases were ubiquitously expressed in the selected tissues, albeit to different degrees. This was confirmed through bioinformatics analyses from publicly available microarray data resources ${ }^{4}\left(\mathrm{BAR}^{5}\right)$, which showed that, under normal conditions, all three kinases are weakly expressed in all tissues (data not shown). MPK18 and MKK3 tissue-specific gene expression was previously investigated using histochemical analysis with the GUS reporter gene under the control of their respective promoters. GUS expression was detected in all major

${ }^{4}$ https://genevestigator.com/gv

${ }^{5}$ http://bbc.botany.utoronto.ca

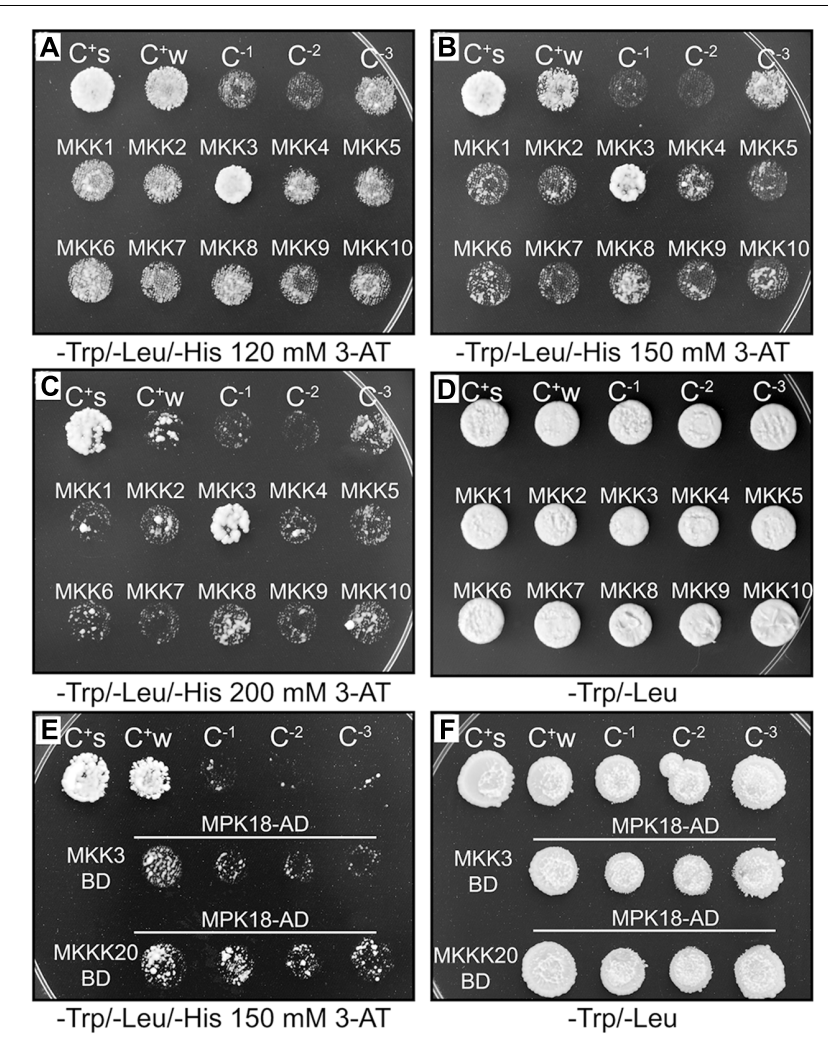

FIGURE 1 | MKKK20/AtMKKs and MKK3/MPK18 yeast two-hybrid interactions. (A-D) MKKK20/AtMKKs interaction screen. MKKK20 interacts strongly with MKK3. All kinases were cloned and sequence-verified prior to their transfer into Gateway ${ }^{\mathrm{TM}}$ yeast two-hybrid bait and prey vectors (pDEST32 and pDEST22 from Invitrogen ${ }^{T M}$ ). The clones, MKKK20 (in pDEST32 vector) as GAL4 DNA-binding domain (DBD) and AtMKKs (in pDEST22 vector) as GAL4-activating domain (AD), were introduced pairwise into the yeast strain MaV203. Interaction strength for HIS3 and URA3 activation assays was scored visually by comparing to the controls. $\mathrm{C}^{+\mathrm{s}}$ : $\mathrm{pEXP}^{\mathrm{TM}}$ 32/Krev1/pEXPTM $22 /$ RalGDS-wt as strong positive interaction

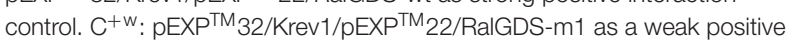

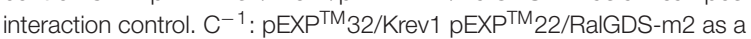
negative interaction control. $\mathrm{C}^{-2}$ : $\mathrm{pDEST}^{\mathrm{TM}} 32 / \mathrm{pDEST}^{\mathrm{TM}} 22$ as a negative activation control. $\mathrm{C}^{-3}$ : $\mathrm{pDEST}^{\mathrm{TM}} \mathrm{MKKK} \mathrm{M} / \mathrm{pDEST}^{\mathrm{TM}} 22$ as a negative activation control. (E,F). MKKK20 and MKK3 interaction with MPK18. MKK3 cloned as DBD and MPK18 as AD. The same controls were used as above except $\mathrm{C}^{-2}$ served as a negative activation control for $\mathrm{MKK} 3$ and $\mathrm{C}^{-2}$ as a negative activation control for MPK18.

tissue types for MPK18 including roots, leaf vasculature, guard cells and stigma (Walia et al., 2009). Likewise, $M K K 3$ was detected in all major tissues (stems, leaves, roots, flowers), with higher GUS activity in the vasculature, stipules, nectaries, and root tips (Lampard, 2006). For MKKK20, transgenic plants were generated to express the GUS reporter gene under the control of a $1.5-\mathrm{kb}$ promoter sequence upstream of the MKKK20 translation start site. Visualization of GUS expression during flower development revealed strong expression in pollen grains increasing from young buds to later stages of maturation (Figures 3A-D), more specifically stages $11-14$. MKKK20 is expressed to a lesser extent in the gynoecium, particularly in the style and 


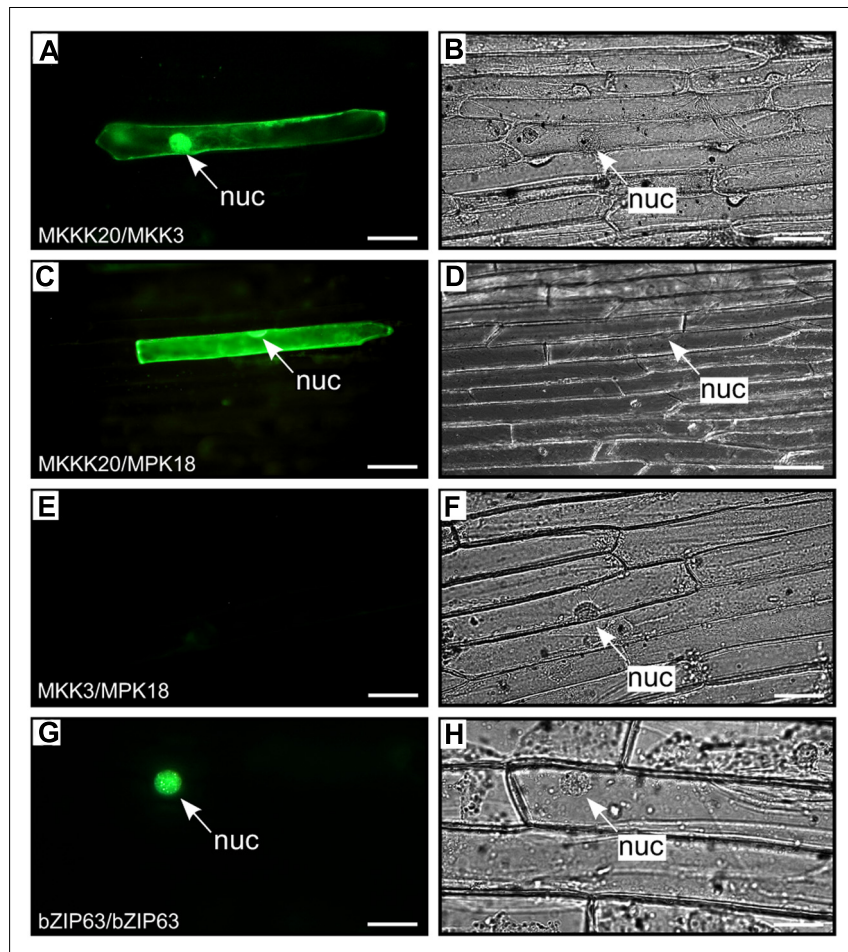

FIGURE 2 | BiFC kinase interaction assays. BiFC visualization of MKKK20 dimerization with MKK3 and MPK18 in onion epidermal cells. Fluorescent (A,C,E,G) and bright field (B,D,F,H) images of epidermal leaf onion cells cotransformed by vectors harboring split YFP and different kinase pairs: MKKK20/MKK3 (A,B); MKKK20/MPK18 (C,D); MKK3/MPK18 (E,F)

Microparticle bombardment was observed under a fluorescence microscope. Full-length cDNAs from the three kinases were cloned in-frame with a split-YFP construct from either BiFC vector pUC-SPYCE or pUC-SPYNE (Walter et al., 2004). The bZIP63 transcription factor was used as positive control for $\operatorname{BiFC}(\mathbf{G}, \mathbf{H})$. Scale bar $=20 \mu \mathrm{m}$.

carpel, but not in the stigma regardless of its developmental stage. MKKK20 is also expressed in nectaries, petals, and sepals (Figures 3A-D). Expression was also detected in pollen tubes (Figure 3D). Expression was also remarkably strong in seedling leaves (Figures 3E-G) and roots (Figures 3H,I). Subcellular localization of the three kinases was also examined. Under control of the CaMV 35 S promoter, MKKK20, MKK3, and MPK18 coding sequences were fused N-terminal to the GFP reporter gene and examined following transient expression in onion leaf epidermal cells using microparticle bombardment. All three kinases were observed both in the cytoplasm and the nucleus (Figure 4), a subcellular localization pattern identical to that determined previously through BiFC interactions (Figure 2). Prediction models based on more than 10 algorithms for each kinase, combined with published curated data sets from the subcellular location database for Arabidopsis proteins (SUBA4 ${ }^{6}$ ) also gave equally nuclear/cytoplasmic localization predictions, in line with the previous subcellular localization assays (Figures 2, 4).

\footnotetext{
${ }^{6}$ http://suba.live
}

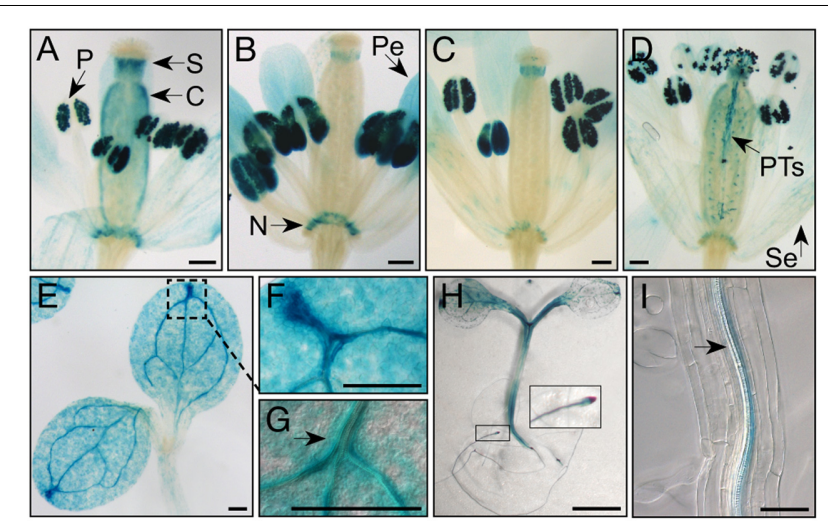

FIGURE 3 | MKKK20 expression pattern monitored by the GUS reporter gene. GUS reporter gene expression under the control of the MKKK20 promoter in flower buds and seedlings. (A-D) Flower developmental stages. (A) Stage 11. (B) Stage 12. (C) Stage 13. (D) Stage 14 (according to Smyth et al., 1990). Strong staining is observed in pollen of maturing flowers. Expression tends to become stronger between stage 11 (A) and at anthesis (D). Global visualization of flower development, after manual opening, confirmed that pollen grains $(\mathrm{P})$ exhibit strong MKKK20 expression, in addition to carpel $(\mathrm{C})$, style $(\mathrm{S})$, nectaries $(\mathrm{N})$, petals $(\mathrm{Pe})$, and sepals $(\mathrm{Se})$, the two later with lesser intensities as they mature (A-D). (D) While pollen expression last after pollination in pollen tube (PT), staining decreases in the others flower organs. Expression can be detected also in some epidermal cells and vascular tissues. (E-G) Expression in cotyledons. (H) Expression in hypocotyl and roots. (I) Expression in companion cells of phloem tissues of roots. Scale bar: $200 \mu \mathrm{m}$, except for $\mathbf{( H )}(5 \mathrm{~mm})$ and $\mathbf{( I )}(100 \mu \mathrm{m})$.

\section{MKKK20 Autophosphorylates and Phosphorylates Both MKK3 and MPK18 In Vitro}

Full-length MKKK20, MKK3, and MPK18 cDNAs were cloned and expressed as His-tag or His-GST-tag proteins in an E. coli system. Kinase activity was measured from in vitro kinase assays and in-gel kinase assays. Firstly, kinase autophosphorylation activity and ability to phosphorylate the MBP generic substrate were tested. Unlike MKK3 (Figures 5B,D) and MPK18 (Figures 5C,D) proteins, MKKK20 strongly autophosphorylates (Figures 5A-D) and phosphorylates MBP (Figures 5A,B,D). Interestingly, migration on SDS-PAGE gels of bacterially expressed MKKK20 revealed the presence of multiple bands with two major MKKK20 isoforms (higher-H and lower- $\mathrm{L}$ isoforms; Figures 5A-D). Differences in phosphorylated residues could explain the migration shift of the various MKKK20 phosphoisoforms in SDS PAGE gels. To test this, MKKK20 was incubated with active or inactivated calf intestinal alkaline phosphatase (CIP) followed by an in-gel kinase assay with MBP as substrate (Figure 5A). Dephosphorylation of MKKK20 as well as its kinase dead version (Figure 5A) led to a single $\mathrm{MW}$ isoform (lower $\mathrm{MW}$ ), confirming that the multi-band pattern from the bacterially expressed MKKK20 is due to differential levels of phosphorylation among isoforms. MKKK20 kinase activity is also heavily dependent on its phosphorylation status since dephosphorylation strongly weakened its activity toward MBP (Figure 5A). Furthermore, 
the MKKK20 higher MW isoform consistently exhibited higher autophosphorylation activity (Figures 5A-D) and greatly increased activity toward the generic substrate MBP (Figure 5A, right panel). Mass spectroscopy analysis of the high and low molecular weight isoforms of MKKK20 revealed differences in phosphorylation sites (Supplementary Figure S2 and Table S7). Six phosphorylated amino acids were unique to HMW or LMW MKKK20/WT protein. Of these, two phosphorylated tyrosine were unique to the MKKK20-HMW. From mass spectrometry data, both MKKK20-HMW and MKKK20-LMW displayed around 20 phosphorylated sites from peptides that covered $40 \%$ of the whole protein. This represents half of the total peptides detected (phosphorylated and non-phosphorylated), which covered $80 \%$ of the complete protein. MKKK20 phosphorylated sites from the high and low molecular weight variants were solely found in the kinase domain, while only a single phosphoserine was found in the kinase dead version of MKKK20, outside of the kinase domain. Next, MKKK20 was incubated with MKK3 and MPK18, separately and in combinations. As expected from the tight interaction between MKKK20 and MKK3 observed in the $\mathrm{Y} 2 \mathrm{H}$ screen, MKKK20 strongly phosphorylated MKK3-WT as well as MKK3-KD, while MKK3-WT and MKK3-KD alone or in the presence of MKKK20-KD neither autophosphorylated nor phosphorylated MBP (Figure 5B). Since MPK18 was also found to directly interact with MKKK20 in the $\mathrm{Y} 2 \mathrm{H}$ screen (Figure 1E), the ability of MKKK20 to phosphorylate MPK18 was also tested. MPK18 alone did not display autophosphorylation activity but was a good substrate for the MKKK20 (Figures 5C,D), confirming the direct interaction with these two kinases, as shown previously from $\mathrm{Y} 2 \mathrm{H}$ and $\mathrm{BiFC}$ assays. When incubated together, MKK3 and MPK18 did not show any reciprocal kinase activity nor did they phosphorylate MBP (Figure 5D). This could suggest that MKK3 needs to be activated by the upstream MKKK20 to phosphorylate the downstream MPK18. However, when the three kinases were incubated together, no synergistic phosphorylation effect was observed on MPK18, suggesting that phosphorylated MKK3 does not phosphorylates MPK18 (Figure 5D). In fact, MKKK20 displayed no obvious phosphorylation preference for either MKK3 or MPK18, both kinases being equally phosphorylated by the MKKK20 (Figure 5D). To further ascertain that MKKK20 directly activates MPK18 and bypass the need of an MKK, an anti-p-ERK antibody that specifically targets the [T-X-Y] MPK activation loop was used. Figure 5E shows that a combination of MKKK20 and MPK18 is sufficient to phosphorylate the MPK18 activation loop TDY motif. Furthermore, when all three kinases are combined, no synergistic effect on MPK18 is found, as observed in the previous kinase assays (Figure 5D), confirming that MKKK20 bypasses the need of an MKK to activate MPK18.

\section{$m k k k 20$ and $m k k 3$ Mutants Are Sensitive to Microtubule-Disrupting Drugs}

Low doses of the microtubule-disrupting inhibitor oryzalin on growing roots are also known to generate a left-handed twisting of the roots (when viewed from above the plates), and both root skewing and root elongation are generally linked

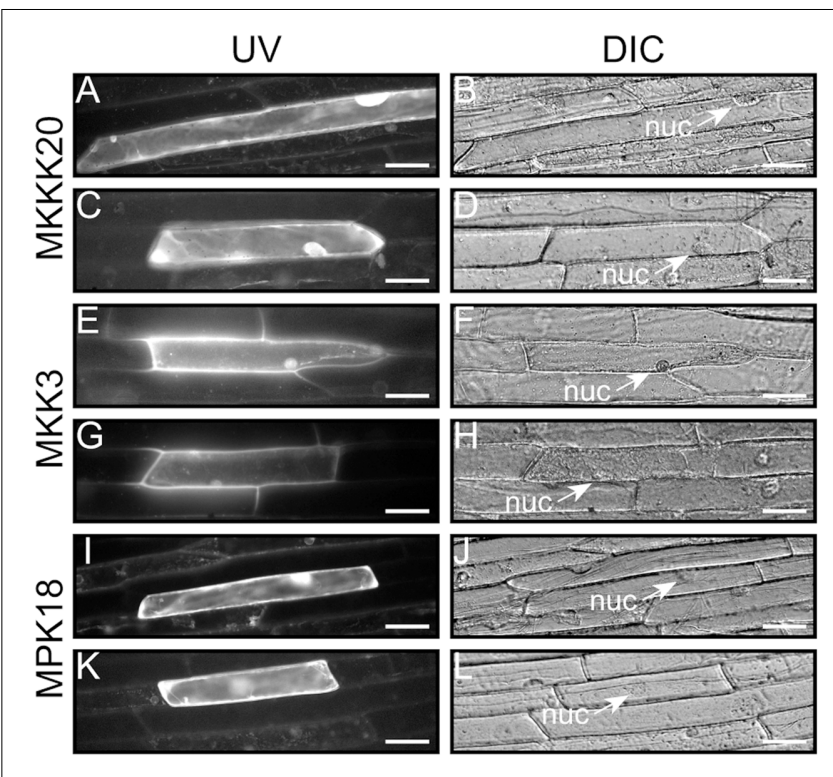

FIGURE 4 | Kinase subcellular localization. Characterization of the MKKK20, MKK3, and MPK18 nuclear and cytosolic localization. The coding regions of the three kinases were fused in-frame to the $\mathrm{N}$-terminus of the GFP reporter in the pMDC83 vector (Curtis and Grossniklaus, 2003). Epifluorescence

$\mathbf{( A , C , E , G , I , K )}$ and bright field $\mathbf{( B , D , F , H , J , L ) ~ i m a g e s ~ o f ~ o n i o n ~ l e a f ~ e p i d e r m a l ~}$ cells show cytosolic and nuclear localization for all three kinases. Scale bar: $50 \mu \mathrm{m}$.

to microtubule organization and stability (Baskin et al., 1994; Thitamadee et al., 2002). Since it had been reported that mpk18 mutant seedlings showed defects in microtubule-related functions (Walia et al., 2009), we next investigated whether $M K K K 20$ and $M K K 3$ were also involved in the same biological process. To do so, T-DNA insertional lines for the three designated kinases $m k k k 20-1, m k k k 20-2, m k k 3-1$, and $m p k 18-1$ we used. Both $m k k k 20$ T-DNA insertion lines as well as $m k k 3-1$ and $m p k 18-1$ were considered null alleles since no mRNA could be amplified by RT-PCR analyses (Supplementary Figure S3). All mutant plants were morphologically analyzed and compared to Arabidopsis wild type plants and no obvious defect was observed at any developmental stages under normal growth conditions. However, seedling roots from $m k k k 20, m k k 3$, and $m p k 18$ plants were significantly shorter $(p<0.001)$ than wild type plants for all oryzalin concentration used (Figures 6A,B). The same phenotype was observed for $m k k k 20-1$ and $m k k k 20-2$ (Supplementary Figure S4; in subsequent experiments only $m k k k 20-1$ is used). Since $m k k k 20, m k k 3$, and $m p k 18$ single mutants showed defects in microtubule organization, analyses of double and triple mutants were undertaken to further explore the relationship between these kinases and microtubule functionality. When all single mutants were reciprocally crossed to each other, only the $m k k k 20 / m k k 3$ double mutant offspring were unviable. The other two double mutant pairs, $m k k k 20 / m p k 18$ and $m k k 3 / m p k 18$, were fully viable. Both double mutants displayed significantly shorter roots compared to all single mutants in the presence of 0.12 and $0.15 \mu \mathrm{M}$ oryzalin. At the highest oryzalin concentration tested $(0.2 \mu \mathrm{M})$, no significant differences 
A

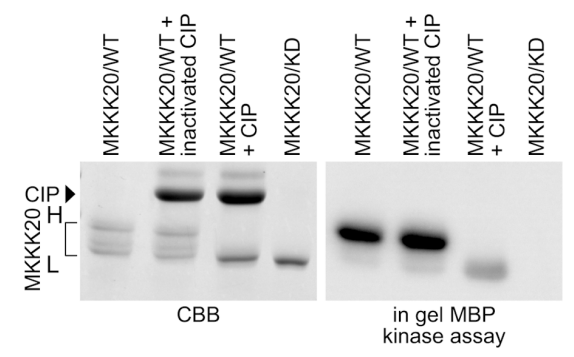

B

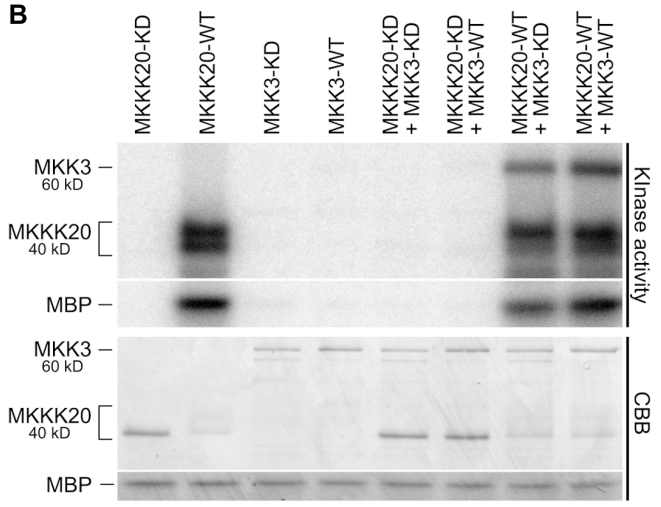

C

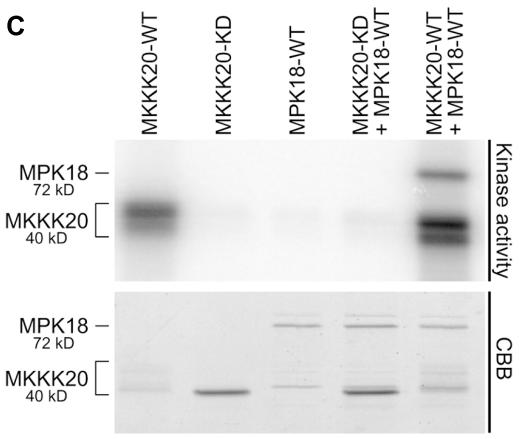

D

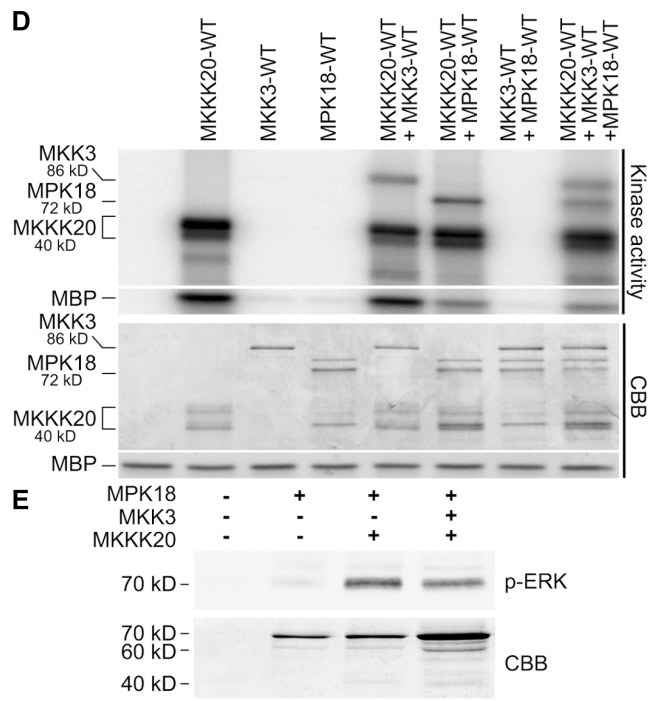

FIGURE 5 | MKKK20 functions upstream of both MKK3 and MPK18. (A) MKKK20 phosphorylation affects electrophoretic mobility and kinase activity. Bacterially expressed MKKK20 shows the presence of multiple bands

(Continued)
FIGURE 5 | Continued

with two major MKKK20 isoforms (see brackets in panels A-D; $\mathrm{H}$ and L, higher and lower MW isoforms, respectively). Left panel: Coomassie Brilliant Blue (CBB) SDS-PAGE gel of WT MKKK20 treated with active or inactivated calf intestinal alkaline phosphatase (CIP) and an MKKK20 kinase dead version. Right panel: In-gel kinase assay with MBP $(0.5 \mathrm{mg} / \mathrm{ml})$ as substrate. In vitro kinase assay of recombinant MKKK20/MKKK20 KD activity with or without MKK3 (B), or MPK18 (C), and with the three kinases combined (D). All 6xHis-tagged proteins were expressed in bacteria and purified on Ni-NTA Sepharose columns. Two different MKK3 constructs were used. In (B) 6xHis-MKK3 and in (D) 6xHis-GST-MKK3. Protein combinations were incubated in kinase assay buffer with $\left[\gamma-{ }^{32} P\right]$-ATP. MBP was also added in the in vitro kinase assays of panels $(\mathbf{B}, \mathbf{D})$ as a universal substrate to assess kinase activity. The bottom panel shows the Coomassie Brilliant Blue-stained SDS/PAGE. WT, wild type kinase; KD, kinase dead; CBB, Coomassie Brilliant Blue. (E) MPK18 activation loop phosphorylation by MKKK20 as observed with an anti-p-ERK antibody specifically targeting the $[T-X-Y]$ motif.

between single and double mutants was observed. Interestingly, root length was affected in the $m k k 3 / m p k 18$ double mutant in the absence of oryzalin (Figures 6A,B). Since obvious lefthanded root twisting was observed (Figure 6A), root skewing angle was also measured. At $0.2 \mu \mathrm{M}$ oryzalin concentration, all single mutants showed leftward skewing (Supplementary Figure S5), as observed previously with the mpk18 mutants (Walia et al., 2009). Functional complementation of $m k k k 20$ and $m k k 3$ plants was accomplished by plant transformation through agro-infiltration with constructs encoding C-terminal His-tagged proteins (p35S::MKKK20-His and p35S::MKK3-His), in their respective mutant plants. Overexpression of the two kinases was verified by western blots in transformed plants with anti-His antibodies (Figures 6C,D). Complementation of single $m k k k 20$ and $m k k 3$ mutants with their respective constructs was fully restored as root length from both complemented mutants regained the WT phenotype under $0.2 \mu \mathrm{M}$ oryzalin treatments (Figure 6E). Close observations of cell shape also showed that at the root elongation zone width was significantly higher than WT for the three single mutants $(p<0.001)$ at the two oryzalin concentrations used (Figure 7A). Elongation zone shape for each mutant is illustrated in Figure 7B.

\section{DISCUSSION}

Among the 21 Arabidopsis MEKKs, MKKK19, -20, and -21 form a highly supported clade within the MEKK family. Paralogous MAPKKKs of this clade have been initially studied in Solanaceous species where they were coined Fertilization-Related Kinases (FRKs) from the first three characterized members in Solanum chacoense (ScFRK1, -2, and -3) (Gray-Mitsumune et al., 2006; O'Brien et al., 2007; Daigle and Matton, 2015; Lafleur et al., 2015). This clade has considerably expanded in the Solanaceae family that includes potato and tomato (Daigle and Matton, 2015). In these two species, the FRK clade represents around $40 \%$ of all MEKKs (15 and 17 FRKs out of 36 and 39 MEKKs, respectively), compared to $14 \%$ (3 out of 21 ) in A. thaliana. The FRK class is further subdivided in four groups. Arabidopsis MKKK19, -20, and -21 belong to group 4 , the most ancient group in dicots, 


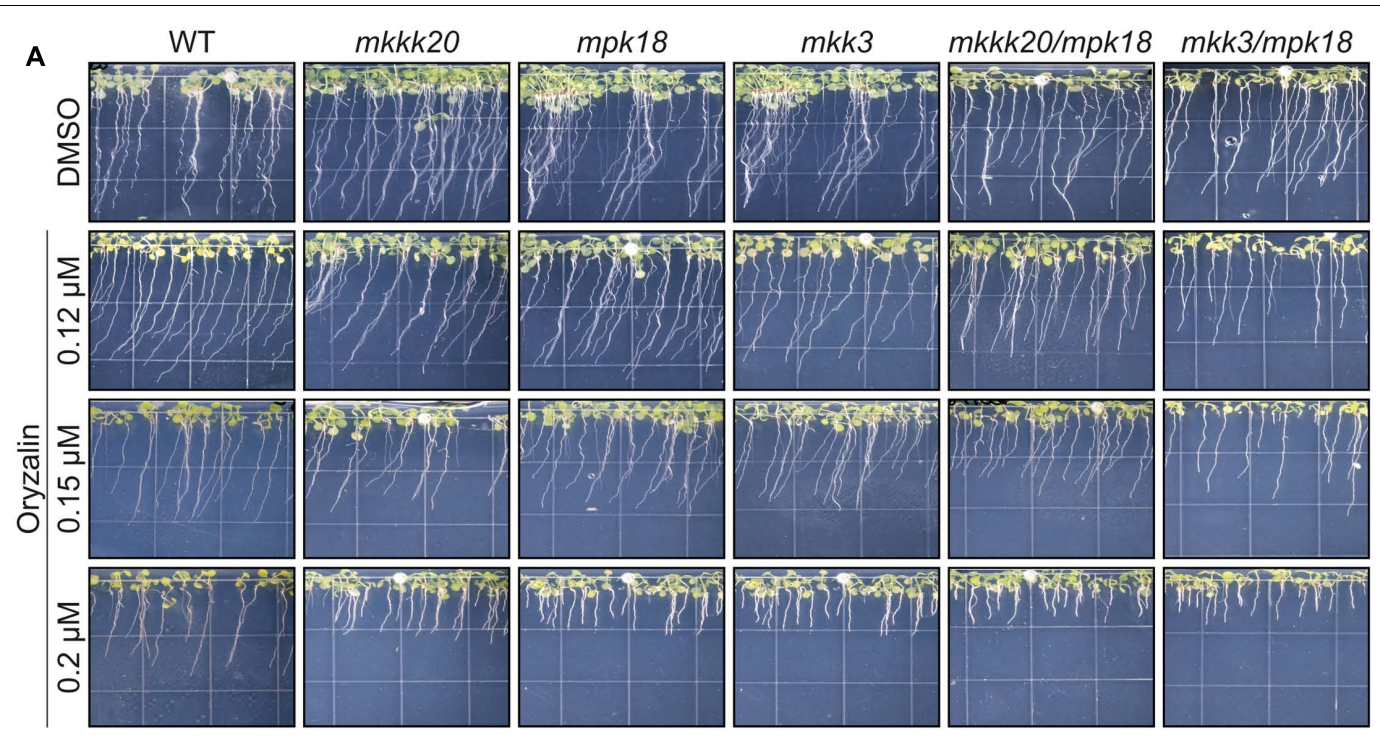

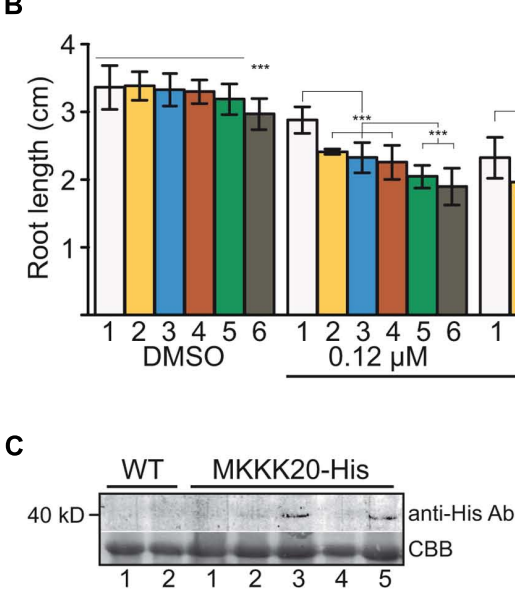

E

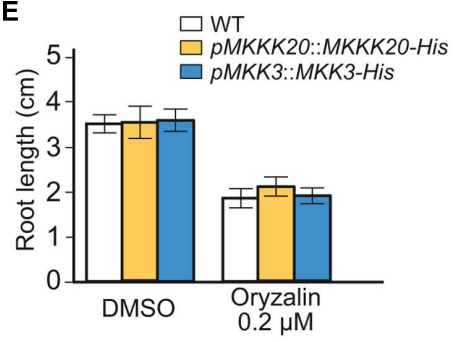

FIGURE 6 | Absence of MKKK20 and MKK3 affects microtubule-related functions. Root length of 8-day-old wild type, single mutant $m k k k 20$ - 1 , $m k k 3$, mpk18, and double mutant $m k k k 20 / m p k 18, m k k 3 / m p k 18$ seedlings grown on DMSO and various concentrations of oryzalin. (A) Whole seedlings were grown vertically in Hoagland medium solidified with 1.2\% agar with different oryzalin concentrations. Root length and skewing angle are shown. (B) Treatments with $0.12,0.15$, and $0.2 \mu \mathrm{M}$ oryzalin significantly reduced the length of all mutant roots compared to the wild type, based on one-way ANOVA multiple comparison with Tukey's test. ${ }^{* * *} p<0.001$ for all treatments. Data represent means $\pm \mathrm{SD}(n \geq 30)$. Significant reductions, if any, in root length between single and double mutants are also indicated. (C-E) MKKK20 and MKK3 complementation. Western blot analyses of His-Tag proteins showing expression of the recombinant kinases in their respective mutant backgrounds MKKK20 (C) and MKK3 (D). Plants 3 and 5 for MKKK20 and samples 1 and 2 for MKK3 were kept to carry out further plants analyses. Upper panel in (C) and (D). Detection of His-Tag proteins was done with a primary mouse anti-poly-histidine antibody, followed by a secondary rabbit anti-mouse lgG-HRP antibody for colorimetric detection. Lower panel in (C) and (D). CBB staining of total protein. (E) Root length of 6-day-old mkkk20 and $m k k 3$ complemented seedlings grown on DMSO and $0.2 \mu \mathrm{M}$ oryzalin. Data represent means $\pm \mathrm{SD}(n \geq 28)$. For the effect of oryzalin on root length in mutants, refer to panel (B).

while the Solanaceae family encompass the four groups. While the role of these three Arabidopsis kinases is largely unknown, except for the role of MKKK20 in osmotic stress (Kim et al., 2012) and in abscisic acid responses (Li et al., 2017), the three characterized Solanaceous FRKs show a clear involvement in male and female reproductive development. Here, we employed genetic and biochemical tools to study the biological significance of the A. thaliana MKKK20. Surprisingly, although MKKK20 is strongly expressed in pollen (Figure 3), no obvious reproductive phenotype was observed in the loss-of-function mutant. Instead, MKKK20 single mutants showed a clear defect in MT functions.
The Y2H screen for MKKK20 interacting partners revealed a strong and robust association with MPK18, a result that suggested the operation of an atypical MAPK pathway that bypasses MKKs (Figure 1E, Y2H and Figure 2C, BiFC). Other MKKKs have been shown to interact with proteins other than MKKs. For example, AtMEKK1 not only interact with, and phosphorylate the transcription factor WRKY53, but can also bind to the promoter region of the WRKY53 gene to increase its relative expression (Miao et al., 2007). Although not considered a MEKK, the Raf-like Constitutive Triple Response1 MKKK (CTR1) interacts with and directly phosphorylates Ethylene-insensitive 2 


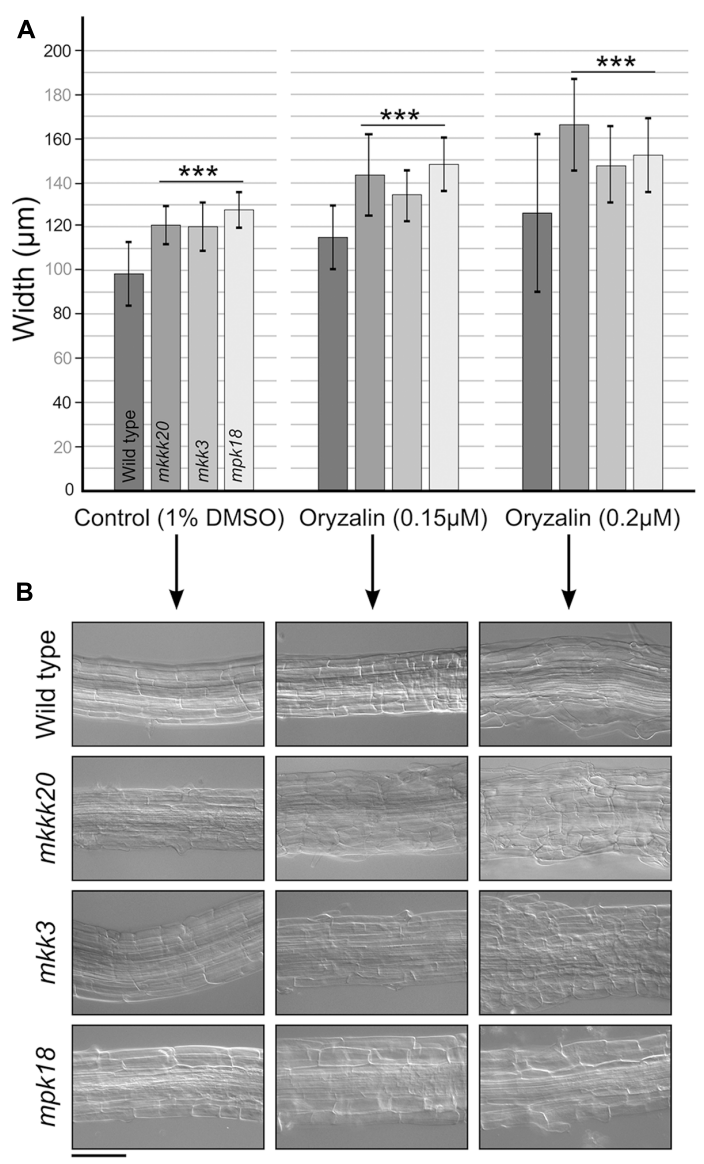

FIGURE 7 | Cell width at the root elongation zone. (A) Width of the root elongation zone. Width was calculated from three elongation zone position (beginning, middle, end) and reported as a mean ( $n \geq 15)$. (B) Representative observation for each single mutant in (A). Data represent mean $\pm S D$. Scale bar: $100 \mu \mathrm{m}$. Student's $t$-test was used to calculate the $p$-value. Highly significant differences ${ }^{* * *} p<0.001$.

(EIN2), which is not a MKK (Ju et al., 2012). In alfalfa, the MKKK OMTK1 (oxidative stress-activated MAP triple-kinase 1), which is activated by hydrogen peroxide, interacts directly with the MMK3 MAPK, thus bypassing the need for an intermediate MKK (Nakagami et al., 2004). Since MAPK cascades are prototypically activated by three-tiered sequential phosphorylation events, the involvement of a MKK in this putative cascade was addressed. A directed pairwise $\mathrm{Y} 2 \mathrm{H}$ assay revealed that, among the 10 AtMKKs, MKK3 showed by far the strongest interaction with MKKK20. However, interaction between MKK3 and MPK18 in two-hybrid assays proved to be very weak compared to the strong MKKK20-MKK3 interaction (Figure 1C). An earlier directed two-hybrid screen between all Arabidopsis MKKs and MPKs, also showed no interaction between MKK3 and MPK18 (Lee et al., 2008), and the weak interaction observed between MKK3 and MPK18 (Figure 1E) was not validated by the BiFC assay (Figures 2E,F) nor by a phosphorylation assay (Figure 5D).

The first results from kinase activity assays demonstrated that MKKK20 autophosphorylates strongly (Figures 5A-D). Since eukaryotic protein kinases (EPKs) catalytic activity depends on phosphorylation of their activation loop, leading to a conversion from inactive to active conformation, the activation loop status of the MKKK20 expressed in bacteria was investigated (Bossemeyer, 1995; Nolen et al., 2004). Interestingly, autophosphorylation of EPKs seemed to be shared by most eukaryotic protein kinases (Beenstock et al., 2016). LC-MS/MS results showed that, inside the activation segment, bordered by the DFG motif in subdomain VII and the APE motif in subdomain VIII, two residues from the MKKK20 activation loop (threonine ${ }^{161}$ and serine $^{166}$ ) were phosphorylated (Supplementary Figure S2). Such phosphorylation is important for MAPKKK activation as demonstrated for human Mixed Lineage Kinase-3 (Leung and Lassam, 2001). In addition, MKKK20 phosphorylates both MKK3 and MPK18 equally, whereas no phosphorylation was observed when MKK3 and MPK18 are incubated together (Figure 5D). When all three kinases were present, MKKK20 phosphorylated equally MKK3 and MPK18. The presence of a phosphorylated MKK3 did not result in any obvious increase in MPK18 phosphorylation. Thus, the evidence suggests that MPK18 is not a bona fide MKK3 target, and that the pattern of activation of these kinases is an exception to the canonical MAPK signaling pathway. As noted above, this is not without precedent. Indeed, three characterized Nicotiana MAPKKKs ( $N b$ MAPKKK $\alpha, N b$ MAPKKK $\beta$, and $N b$ MAPKKK $\gamma$ ) were found to form a linear cascade leading to programmed cell death in tobacco cells (Hashimoto et al., 2012). On the other hand, our two-hybrid analysis and kinase assays demonstrated that MKKK20 interacts with and phosphorylates both MKK3 and MPK18.

Arabidopsis MPK18 had previously been shown to mediate cortical microtubule functions (Walia et al., 2009). Loss-offunction mutation in MPK 18 results in more stable microtubule arrays and $m p k 18$ roots display more abundant and better coaligned microtubule polymers in their elongation zones as a result of MT dynamic instability problems (Walia et al., 2009). When treated with oryzalin, the $m k k k 20$ mutant displayed significantly diminished seedling root length compared to the similarly treated wild type plants (Figures 6A,B). This phenotype is similar to the one observed in $m p k 18$ plants, suggesting that both MKKK20 and MPK18 could be participating in a MAPK signaling pathway that mediates cortical microtubule function. In addition, $m k k 3$ mutant roots, like $m k k k 20$ and $m p k 18$, were significantly shortened when treated with oryzalin, suggesting that these three kinases could be involved in a classical MAPK cascade. Thus, experimental evidence from both genetic and biochemical studies suggested the involvement of MKKK20, MKK3, and MPK18 in cortical microtubule functions in Arabidopsis cells, but in more than one signaling cascade. Since no protein-protein interaction or phosphorylation was observed between MKK3 and MPK18, this suggests that these three kinases act through two independent pathways involved in MT functions. The first would represent a canonical MAPK cascade, consisting of MKKK20, MKK3, and an as yet-unknown MAPK, while the second would be a non-canonical MAPK cascade with MKKK20 and MPK18 interacting directly, thus bypassing the need for a MKK intermediary. MKKK20 would therefore activate 
MKK3, which could in turn target downstream MAPKs (other than MPK18) involved in microtubule functions. Alternatively, MKKK20 could directly interact with MPK18 that would activate other target(s) (e.g., MAPs), modulating microtubule functions. Such direct MPK18 activation through phosphorylation of its activation loop TDY motif was validated using an anti-p-ERK antibody that specifically targets the [T-X-Y] MPK18 activation loop (Figure 5E). Interestingly, another D-type member, MPK9, was also shown to be activated through an independent MAPK cascade manner (Nagy et al., 2015).

Regarding the first pathway, two MPKs involved in MT functions had been previously found to interact with MKK3: MPK4 and MPK6 (Popescu et al., 2009). MPK4 acts downstream from two MKKKs (ANP1-2; also known as MKKK1 and MKKK2) involved in microtubule organization (Beck et al., 2010, 2011). In addition, MPK4 phosphorylates the microtubuleassociated proteins AtMAP65-1 and AtMAP65-2, which are two structural components of microtubule arrays involved in cell division (Sasabe et al., 2011), and possess canonical serine/threonine-proline MAPK phosphorylation sites. MPK6 has been functionally linked to MTs since it localizes to the plasma membrane and is involved in root development and cell division control (Muller et al., 2010). MPK6 has been also shown to interact with $\gamma$-tubulin and the MT plus end protein EB1 (Kohoutova et al., 2015). Thus, both MPK4 and MPK6 represent strong candidates for completing the proposed MKKK20/MKK3 module. It is worth mentioning that MKK3 plays an essential role in the activation of MPK6 through the phytohormone jasmonic acid (JA; Takahashi et al., 2007). In a large microarray transcriptional analysis of several MAPK signaling genes, jasmonates were also found to induce transcription of MKKK20 (Menges et al., 2008). Thus, under the influence of JA, MKKK20 could potentially activate the MKK3/MPK6 cascade thereby affecting MT function. Interestingly, JA treatment induces changes in the orientation of cortical MTs during potato tuberization and cell expansion, consistent with the idea that JA might control the direction of cell expansion by changing the arrangement of MTs (Koda, 1997; Cenzano et al., 2003). Recently, a MKKK20-MKK5-MPK6 cascade was also shown to modulate abscisic acid responses, regulating cell division and cell elongation mainly at the root elongation zone (Li et al., 2017). As for MKK5, MKK4 was also shown to interact with MKKK20 in a BiFC assay. Surprisingly, previous results from the Brassica napus MKKK20 ortholog (BnaMKKK20; Sun et al., 2014), showed no interaction between BnaMKKK20 and BnaMKK4 or BnaMKK5, a result also observed in our $\mathrm{Y} 2 \mathrm{H}$ assay with the $A$. thaliana MKKK20 (Figure 1). Furthermore, MKKK20 from A. thaliana (Figure 1) and B. napus (Sun et al., 2014) strongly interacted with $\mathrm{MKK} 3$, in both $\mathrm{Y} 2 \mathrm{H}$ and $\mathrm{BiFC}$ assays. It is noteworthy to mention that in this case, different BiFC assay systems (microparticle bombardment vs Agrobacterium infiltration) were used. The MKKK20-MKK3 Y2H interaction was also recently mentioned in (Colcombet et al., 2016), emphasizing the strong interaction between MKKK20 and MKK3. Taken together, the short root phenotype observed in $m k k k 20$ plants could result in overlapping functions of MKKK20 in microtubule organization and ABA responses. Interestingly, it had been demonstrated that ABA modulates microtubule organization and stability (Sakiyama and Shibaoka, 1990; Sakiyama-Sogo and Shibaoka, 1993; Takatani et al., 2015). Likewise, the same MPK cascade elements can be involved in different biological contexts (Meszaros et al., 2007; Colcombet et al., 2016). Our results indicate that MKKK20 would act in separate cascades in response to different stimuli.

Overall, our results showed that MKKK20 plays a role in plant root microtubule functions, thereby affecting root growth and development. Two distinct processes regulate plant organ growth; production of cells and expansion. Root growth rate is determined primarily by expansion, yet is also influenced by cell division and production (Beemster and Baskin, 1998). Indeed, it has been reported that the growth of Arabidopsis roots was accompanied by increased cell production leading to cell elongation (Baskin et al., 1995). Cortical as well as mitotic microtubules play an essential role in both elongation and division, and a wide range of MAPs (microtubule-associated proteins) have been associated with these developmental stages in plant cells (Hamada, 2014). It has been shown that the phosphorylation state of MAPs influences microtubule stability (Drechsel et al., 1992; Mandelkow et al., 1995), and phosphorylation of MAPs leads to reduced binding to the microtubule cytoskeleton due to a reduction in MAP-microtubule affinity (Drewes et al., 1998). Our results are consistent with the idea that these potentially convergent phosphorylation-based signaling pathways play a role in controlling microtubule dynamics. The binding of specific MAPs to MTs results in structural regulation via interconnected polymerization/catastrophe events collectively referred to as dynamic instability (Hamada, 2014). Some of these MAPs play crucial roles in microtubule orientation or anisotropy. This could be explained by a model in which some structural MAPs (downstream of the canonical and non-canonical MKKK20 cascades) would be lesser phosphorylated in the absence of MKKK20, resulting in their higher affinity for MT polymer chains (Nogales, 2000), and perturbation of the normal array alignment. Therefore, such perturbation could affect directly the normal growth of the plant cell wall, cortical microtubule functions being disturbed, as observed in the elongation zone (Figure 7). The two MKKK20 pathways, one that includes MPK18, and the other MKK3 (possibly with MPK4 or MPK6), are likely to target different MAPs and exert different influences on MT dynamics and organization. Indeed, the phenotype of $m p k 18$ is not as dramatic as that of $m p k 4$ (Komis et al., 2011) and MPK4 was found to co-localize with microtubules, unlike MPK18 (Walia et al., 2009). Moreover, inhibition of phosphorylation via the $m k k 3$ mutation is likely to cause MT hyperstabilization, as seen with mpk18-1 mutant (Walia et al., 2009). The summation of different pathway disturbances in the $m k k k 20$ mutant could therefore lead to more drastic perturbation of microtubule dynamics. This is supported by the observation that, in the absence of oryzalin, the $m k k 3 / m p k 18$ double mutant root length is significantly shorter than in all other lines (Figures 6A,B). Our understanding of the role played by plant MAPK signaling in regulating microtubule functions still needs to be refined. The involvement of multiple MAPK members in numerous biological processes often compromises a clear understanding 
of phenotypic specificity. Full characterization of the signaling network, including cross talk between parallel cascades, will ultimately be needed to develop a coherent biological picture.

\section{AUTHOR CONTRIBUTIONS}

$\mathrm{RB}, \mathrm{FB}, \mathrm{SD}$, and $\mathrm{AL}-\mathrm{H}$ carried out the experiments. BE provided study materials and critical revision of the manuscript. $\mathrm{RB}$ and DM designed most experiments and wrote the manuscript.

\section{FUNDING}

This work was supported by NSERC (Natural Sciences and Engineering Research Council of Canada) and from the FRQ-NT (Fonds de recherche du Québec - Nature et technologies).

\section{ACKNOWLEDGMENT}

We thank Valentin Joly for the gene ontology analysis of the MKKK20 interacting proteins.

\section{SUPPLEMENTARY MATERIAL}

The Supplementary Material for this article can be found online at: http://journal.frontiersin.org/article/10.3389/fpls.2017.01352/ full\#supplementary-material

FIGURE S1 | Kinase expression patterns assessed by RT-PCR. RT-PCR analysis of $M K K K 20, M K K 3$, and MPK18 gene expression in various organs of Arabidopsis thaliana. The actin2 gene was used as an internal control for equal loading. Specific primers for each gene can be found in Supplementary Table S3. Twenty-four cycles were performed for MKKK20, MKK3, and MPK18, while 20 cycles were used for Act2.

FIGURE S2 | MKKK20 autophosphorylation in bacteria. LC-MS/MS MKKK20 phosphosites analysis from WT and kinase dead protein expressed in bacteria.

\section{REFERENCES}

Asai, T., Tena, G., Plotnikova, J., Willmann, M. R., Chiu, W. L., Gomez-Gomez, L., et al. (2002). MAP kinase signalling cascade in Arabidopsis innate immunity. Nature 415, 977-983. doi: 10.1038/415977a

Baskin, T. I., Cork, A., Williamson, R. E., and Gorst, J. R. (1995). STUNTED PLANT 1, a gene required for expansion in rapidly elongating but not in dividing cells and mediating root growth responses to applied cytokinin. Plant Physiol. 107, 233-243. doi: 10.1104/pp.107.1.233

Baskin, T. I., Wilson, J. E., Cork, A., and Williamson, R. E. (1994). Morphology and microtubule organization in Arabidopsis roots exposed to oryzalin or taxol. Plant Cell Physiol. 35, 935-942.

Beck, M., Komis, G., Muller, J., Menzel, D., and Samaj, J. (2010). Arabidopsis homologs of nucleus- and phragmoplast-localized kinase 2 and 3 and mitogenactivated protein kinase 4 are essential for microtubule organization. Plant Cell 22, 755-771. doi: 10.1105/tpc.109.071746

Beck, M., Komis, G., Ziemann, A., Menzel, D., and Samaj, J. (2011). Mitogenactivated protein kinase 4 is involved in the regulation of mitotic and cytokinetic microtubule transitions in Arabidopsis thaliana. New Phytol 189, 1069-1083. doi: 10.1111/j.1469-8137.2010.03565.x
His-Tag MKKK20/WT and MKKK20-KD proteins expressed in bacteria were separated on SDS-PAGE gel. MKKK20/WT high and low molecular weight bands as well as MKKK20-KD were excised and sent for mass spectrometry analyses. Phosphorylated serine (S), threonine (T), and tyrosine $(Y)$ are shown in red, blue, and green, respectively. Full gray bar represents the coverage of the phosphorylated peptides from the four MKKK20/WT experiments. Dashed gray bar represent an extra single phosphorylated peptide found in MKKK20-LMW-1. Black bar represents the overall peptide coverage observed for all MKKK2O proteins. Asterisks indicate the six phosphorylated Ser, Thr, or Tyr that are unique to HMW or LMW MKKK20/WT. For identification of MS/MS peptides, see Supplementary Table S7.

FIGURE S3 | RT-PCR showing lack of MKKK20-1, MKKK20-2, MKK3, and MPK18 transcript in 10-day-old seedlings from each T-DNA mutant. RT-PCR product from five different seedlings are shown for $m k k k 20-1,-2$ (A), $m k k 3$ (B), and $m p k 18$ (C) side by side with wild type using specific primers corresponding to each of the three genes. No amplification was observed with cDNA from mkkk20-1, -2 likewise, no expression was seen for mkk3 and mpk18 after 32 cycles for each gene. The same number of cycle was as used for the actin2 as an internal control. All gene-specific primers are listed on Supplementary Table S2.

FIGURE S4 | MKKK20 T-DNA insertional mutant phenotype. Root length (A) and skewing angle (B) of 8-day-old single $m k k k 20-1$ and $m k k k 20-2$ mutant seedlings grown on DMSO and with various concentrations of oryzalin. Both MKKK2O T-DNA mutant lines showed identical behavior.

FIGURE S5 | Mutants root skewing angle. The root skewing angle from 6-day-old WT, mkkk20-1, mpk18, mkk3, mkkk20/mpk18, and mkk3/mpk18 were measured. Oryzalin $(0.2 \mu \mathrm{M})$ treatment induced significantly lower root-skewing angle in all mutants comparing to the wild type. Results are expressed as means $\pm \mathrm{SD}$ ( $n \geq 28$ ). Three distinct groups were calculated a, b, and $c$ based on one-way ANOVA multiple comparison with Tukey's test, ${ }^{* * *} p<0.001$.

TABLE S1 | T-DNA insertion lines.

TABLE S2 | Primers used for T-DNA lines genotyping.

TABLE S3 | Primers used for promoter-GUS constructs and RT-PCR analyses.

TABLE S4 | Primers used for protein expression constructs.

TABLE S5 | Primers used for $m k k k 20$ and $m k k 3$ complementation constructs.

TABLE S6 | Gene ontology analysis of MKKK20 interacting proteins.

TABLE S7 | LC-MS/MS peptide sequencing data.

Beemster, G. T., and Baskin, T. I. (1998). Analysis of cell division and elongation underlying the developmental acceleration of root growth in Arabidopsis thaliana. Plant Physiol. 116, 1515-1526. doi: 10.1104/pp.116. 4.1515

Beenstock, J., Mooshayef, N., and Engelberg, D. (2016). How do protein kinases take a selfie (autophosphorylate)? Trends Biochem. Sci. 41, 938-953. doi: 10.1016/j.tibs.2016.08.006

Bossemeyer, D. (1995). Protein kinases-structure and function. FEBS Lett. 369, 57-61. doi: 10.1016/0014-5793(95)00580-3

Cenzano, A., Vigliocco, A., Kraus, T., and Abdala, G. (2003). Exogenously applied jasmonic acid induces changes in apical meristem morphology of potato stolons. Ann. Bot. 91, 915-919. doi: 10.1093/aob/mcg098

Chang, L., and Karin, M. (2001). Mammalian MAP kinase signalling cascades. Nature 410, 37-40. doi: 10.1038/35065000

Chen, X., Wu, S., Liu, Z., and Friml, J. (2016). Environmental and endogenous control of cortical microtubule orientation. Trends Cell Biol. 26, 409-419. doi: $10.1016 /$ j.tcb.2016.02.003

Colcombet, J., and Hirt, H. (2008). Arabidopsis MAPKs: a complex signalling network involved in multiple biological processes. Biochem. J. 413, 217-226. doi: 10.1042/BJ20080625 
Colcombet, J., Sozen, C., and Hirt, H. (2016). Convergence of multiple MAP3Ks on MKK3 identifies a set of novel stress MAPK modules. Front. Plant Sci. 7:1941. doi: $10.3389 /$ fpls.2016.01941

Curtis, M. D., and Grossniklaus, U. (2003). A gateway cloning vector set for highthroughput functional analysis of genes in planta. Plant Physiol. 133, 462-469. doi: 10.1104/pp.103.027979

Dai, Y., Wang, H., Li, B., Huang, J., Liu, X., Zhou, Y., et al. (2006). Increased expression of MAP KINASE KINASE7 causes deficiency in polar auxin transport and leads to plant architectural abnormality in Arabidopsis. Plant Cell 18, 308-320. doi: 10.1105/tpc.105.037846

Daigle, C., and Matton, D. P. (2015). Genome-wide analysis of MAPKKKs shows expansion and evolution of a new MEKK class involved in solanaceous species sexual reproduction. BMC Genomics 16:1037. doi: 10.1186/s12864-015-2228-3

Danquah, A., de Zelicourt, A., Boudsocq, M., Neubauer, J., Frei Dit Frey, N., Leonhardt, N., et al. (2015). Identification and characterization of an ABAactivated MAP kinase cascade in Arabidopsis thaliana. Plant J. 82, 232-244. doi: $10.1111 /$ tpj. 12808

Dixit, R., Chang, E., and Cyr, R. (2006). Establishment of polarity during organization of the acentrosomal plant cortical microtubule array. Mol. Biol. Cell 17, 1298-1305. doi: 10.1091/mbc.E05-09-0864

Doczi, R., Brader, G., Pettko-Szandtner, A., Rajh, I., Djamei, A., Pitzschke, A., et al. (2007). The Arabidopsis mitogen-activated protein kinase kinase MKK3 is upstream of group C mitogen-activated protein kinases and participates in pathogen signaling. Plant Cell 19, 3266-3279. doi: 10.1105/tpc.106.050039

Drechsel, D. N., Hyman, A. A., Cobb, M. H., and Kirschner, M. W. (1992). Modulation of the dynamic instability of tubulin assembly by the microtubuleassociated protein tau. Mol. Biol. Cell 3, 1141-1154. doi: 10.1091/mbc.3.10. 1141

Drewes, G., Ebneth, A., and Mandelkow, E. M. (1998). MAPs, MARKs and microtubule dynamics. Trends Biochem. Sci. 23, 307-311. doi: 10.1016/S09680004(98)01245-6

Ehrhardt, D. W., and Shaw, S. L. (2006). Microtubule dynamics and organization in the plant cortical array. Annu. Rev. Plant Biol. 57, 859-875. doi: 10.1146/ annurev.arplant.57.032905.105329

Elion, E. A. (2000). Pheromone response, mating and cell biology. Curr. Opin. Microbiol. 3, 573-581. doi: 10.1016/S1369-5274(00)00143-0

Fanger, G. R., Gerwins, P., Widmann, C., Jarpe, M. B., and Johnson, G. L. (1997). MEKKs, GCKs, MLKs, PAKs, TAKs, and tpls: upstream regulators of the c-Jun amino-terminal kinases? Curr. Opin. Genet. Dev. 7, 67-74. doi: 10.1016/S0959437X(97)80111-6

Gao, M., Liu, J., Bi, D., Zhang, Z., Cheng, F., Chen, S., et al. (2008). MEKK1, MKK1/MKK2 and MPK4 function together in a mitogen-activated protein kinase cascade to regulate innate immunity in plants. Cell Res. 18, 1190-1198. doi: $10.1038 /$ cr.2008.300

Garrington, T. P., and Johnson, G. L. (1999). Organization and regulation of mitogen-activated protein kinase signaling pathways. Curr. Opin. Cell Biol. 11, 211-218. doi: 10.1016/S0955-0674(99)80028-3

Germain, H., Gray-Mitsumune, M., Lafleur, E., and Matton, D. P. (2008). ScORK17, a transmembrane receptor-like kinase predominantly expressed in ovules is involved in seed development. Planta 228, 851-862. doi: 10.1007/ s00425-008-0787-0

Gray-Mitsumune, M., O’Brien, M., Bertrand, C., Tebbji, F., Nantel, A., and Matton, D. P. (2006). Loss of ovule identity induced by overexpression of the fertilization-related kinase 2 (ScFRK2), a MAPKKK from Solanum chacoense. J. Exp. Bot. 57, 4171-4187. doi: 10.1093/jxb/erl194

Hamada, T. (2014). Microtubule organization and microtubule-associated proteins in plant cells. Int. Rev. Cell Mol. Biol. 312, 1-52. doi: 10.1016/B978-0-12800178-3.00001-4

Harrison, S. J., Mott, E. K., Parsley, K., Aspinall, S., Gray, J. C., and Cottage, A. (2006). A rapid and robust method of identifying transformed Arabidopsis thaliana seedlings following floral dip transformation. Plant Methods 2:19. doi: 10.1186/1746-4811-2-19

Hashimoto, M., Komatsu, K., Maejima, K., Okano, Y., Shiraishi, T., Ishikawa, K., et al. (2012). Identification of three MAPKKKs forming a linear signaling pathway leading to programmed cell death in Nicotiana benthamiana. BMC Plant Biol. 12:103. doi: 10.1186/1471-2229-12-103

Hoshi, M., Ohta, K., Gotoh, Y., Mori, A., Murofushi, H., Sakai, H., et al. (1992). Mitogen-activated-protein-kinase-catalyzed phosphorylation of microtubule-associated proteins, microtubule-associated protein 2 and microtubule-associated protein 4, induces an alteration in their function. Eur. J. Biochem. 203, 43-52. doi: 10.1111/j.1432-1033.1992.tb19825.x

Ichimura, K., and Group, M. (2002). Mitogen-activated protein kinase cascades in plants: a new nomenclature. Trends Plant Sci. 7, 301-308. doi: 10.1016/S13601385(02)02302-6

Jin, H., Axtell, M. J., Dahlbeck, D., Ekwenna, O., Zhang, S., Staskawicz, B., et al. (2002). NPK1, an MEKK1-like mitogen-activated protein kinase kinase kinase, regulates innate immunity and development in plants. Dev. Cell 3, 291-297. doi: 10.1016/S1534-5807(02)00205-8

Ju, C., Yoon, G. M., Shemansky, J. M., Lin, D. Y., Ying, Z. I., Chang, J., et al. (2012). CTR1 phosphorylates the central regulator EIN2 to control ethylene hormone signaling from the ER membrane to the nucleus in Arabidopsis. Proc. Natl. Acad. Sci. U.S.A. 109, 19486-19491. doi: 10.1073/pnas.12148 48109

Kim, J. M., Woo, D. H., Kim, S. H., Lee, S. Y., Park, H. Y., Seok, H. Y., et al. (2012). Arabidopsis MKKK20 is involved in osmotic stress response via regulation of MPK6 activity. Plant Cell Rep. 31, 217-224. doi: 10.1007/s00299-011-1157-0

Koda, Y. (1997). Possible involvement of jasmonates in various morphogenic events. Physiol. Plant. 100, 639-646. doi: 10.1111/j.1399-3054.1997.tb03070.x

Kohoutova, L., Kourova, H., Nagy, S. K., Volc, J., Halada, P., Meszaros, T., et al. (2015). The Arabidopsis mitogen-activated protein kinase 6 is associated with gamma-tubulin on microtubules, phosphorylates EB1c and maintains spindle orientation under nitrosative stress. New Phytol. 207, 1061-1074. doi: 10.1111/ nph. 13501

Komis, G., Illes, P., Beck, M., and Samaj, J. (2011). Microtubules and mitogenactivated protein kinase signalling. Curr. Opin. Plant Biol. 14, 650-657. doi: 10.1016/j.pbi.2011.07.008

Lafleur, E., Kapfer, C., Joly, V., Liu, Y., Tebbji, F., Daigle, C., et al. (2015). The FRK1 mitogen-activated protein kinase kinase kinase (MAPKKK) from Solanum chacoense is involved in embryo sac and pollen development. J. Exp. Bot. 66, 1833-1843. doi: 10.1093/jxb/eru524

Lampard, G. (2006). Analysis of Signaling from an Unusual MAPKK (AtMKK3) in Arabidopsis thaliana. Ph.D. thesis, University of British Columbia, Vancouver, BC.

Lee, H. (2015). Mitogen-activated protein kinase kinase 3 is required for regulation during dark-light transition. Mol. Cells 38, 651-656. doi: 10.14348/molcells. 2015.0055

Lee, J. S., Huh, K. W., Bhargava, A., and Ellis, B. E. (2008). Comprehensive analysis of protein-protein interactions between Arabidopsis MAPKs and MAPK kinases helps define potential MAPK signalling modules. Plant Signal. Behav. 3, 1037-1041. doi: 10.4161/psb.3.12.6848

Leung, I. W., and Lassam, N. (2001). The kinase activation loop is the key to mixed lineage kinase-3 activation via both autophosphorylation and hematopoietic progenitor kinase 1 phosphorylation. J. Biol. Chem. 276, 1961-1967. doi: $10.1074 /$ jbc.M004092200

Li, K., Yang, F., Zhang, G., Song, S., Li, Y., Ren, D., et al. (2017). AIK1, A mitogen-activated protein kinase, modulates abscisic acid responses through the MKK5-MPK6 kinase cascade. Plant Physiol. 173, 1391-1408. doi: 10.1104/ pp. 16.01386

Liu, Y., Lagowski, J., Sundholm, A., Sundberg, A., and Kulesz-Martin, M. (2007). Microtubule disruption and tumor suppression by mitogen-activated protein kinase phosphatase 4. Cancer Res. 67, 10711-10719. doi: 10.1158/0008-5472. CAN-07-1968

Liu, Y., Schiff, M., and Dinesh-Kumar, S. P. (2004). Involvement of MEK1 MAPKK, NTF6 MAPK, WRKY/MYB transcription factors, COI1 and CTR1 in $\mathrm{N}$-mediated resistance to tobacco mosaic virus. Plant J. 38, 800-809. doi: $10.1111 /$ j.1365-313X.2004.02085.x

Lloyd, C., and Chan, J. (2008). The parallel lives of microtubules and cellulose microfibrils. Curr. Opin. Plant Biol. 11, 641-646. doi: 10.1016/j.pbi.2008.10.007

Lu, K., Guo, W., Lu, J., Yu, H., Qu, C., Tang, Z., et al. (2015). Genome-wide survey and expression profile analysis of the Mitogen-Activated Protein Kinase (MAPK) gene family in Brassica rapa. PLoS ONE 10:e0132051. doi: 10.1371/ journal.pone. 0132051

Mandelkow, E. M., Biernat, J., Drewes, G., Gustke, N., Trinczek, B., and Mandelkow, E. (1995). Tau domains, phosphorylation, and interactions with microtubules. Neurobiol. Aging 16, 355-362. doi: 10.1016/0197-4580(95) 00025-A 
Meng, X., Wang, H., He, Y., Liu, Y., Walker, J. C., Torii, K. U., et al. (2012). A MAPK cascade downstream of ERECTA receptor-like protein kinase regulates Arabidopsis inflorescence architecture by promoting localized cell proliferation. Plant Cell 24, 4948-4960. doi: 10.1105/tpc.112.104695

Menges, M., Doczi, R., Okresz, L., Morandini, P., Mizzi, L., Soloviev, M., et al. (2008). Comprehensive gene expression atlas for the Arabidopsis MAP kinase signalling pathways. New Phytol. 179, 643-662. doi: 10.1111/j.1469-8137.2008. 02552.x

Meszaros, T., Helfer, A., and Bogre, L. (2007). The more we know, the less we understand?: complexity of MAP kinase signaling. Plant Signal. Behav. 2, 30-32. doi: $10.4161 /$ psb.2.1.3885

Miao, Y., Laun, T. M., Smykowski, A., and Zentgraf, U. (2007). Arabidopsis MEKK1 can take a short cut: it can directly interact with senescence-related WRKY53 transcription factor on the protein level and can bind to its promoter. Plant Mol. Biol. 65, 63-76. doi: 10.1007/s11103-007-9198-z

Muller, J., Beck, M., Mettbach, U., Komis, G., Hause, G., Menzel, D., et al. (2010). Arabidopsis MPK6 is involved in cell division plane control during early root development, and localizes to the pre-prophase band, phragmoplast, transGolgi network and plasma membrane. Plant J. 61, 234-248. doi: 10.1111/j.1365313X.2009.04046.x

Nagy, S. K., Darula, Z., Kallai, B. M., Bogre, L., Banhegyi, G., Medzihradszky, K. F., et al. (2015). Activation of AtMPK9 through autophosphorylation that makes it independent of the canonical MAPK cascades. Biochem. J. 467, 167-175. doi: 10.1042/BJ20141176

Nakagami, H., Kiegerl, S., and Hirt, H. (2004). OMTK1, a novel MAPKKK, channels oxidative stress signaling through direct MAPK interaction. J. Biol. Chem. 279, 26959-26966. doi: 10.1074/jbc.M312662200

Nakamura, S., Pourkheirandish, M., Morishige, H., Kubo, Y., Nakamura, M., Ichimura, K., et al. (2016). Mitogen-activated protein kinase kinase 3 regulates seed dormancy in barley. Curr. Biol. 26, 775-781. doi: 10.1016/j.cub.2016. 01.024

Nogales, E. (2000). Structural insights into microtubule function. Annu. Rev. Biochem. 69, 277-302. doi: 10.1146/annurev.biochem.69.1.277

Nolen, B., Taylor, S., and Ghosh, G. (2004). Regulation of protein kinases; controlling activity through activation segment conformation. Mol. Cell 15, 661-675. doi: 10.1016/j.molcel.2004.08.024

O’Brien, M., Gray-Mitsumune, M., Kapfer, C., Bertrand, C., and Matton, D. P. (2007). The ScFRK2 MAP kinase kinase kinase from Solanum chacoense affects pollen development and viability. Planta 225, 1221-1231. doi: 10.1007/s00425006-0432-8

Popescu, S. C., Popescu, G. V., Bachan, S., Zhang, Z., Gerstein, M., Snyder, M., et al. (2009). MAPK target networks in Arabidopsis thaliana revealed using functional protein microarrays. Genes Dev. 23, 80-92. doi: 10.1101/gad.1740009

Popescu, S. C., Popescu, G. V., Bachan, S., Zhang, Z., Seay, M., Gerstein, M., et al. (2007). Differential binding of calmodulin-related proteins to their targets revealed through high-density Arabidopsis protein microarrays. Proc. Natl. Acad. Sci. U.S.A. 104, 4730-4735. doi: 10.1073/pnas.0611615104

Posas, F., and Saito, H. (1997). Osmotic activation of the HOG MAPK pathway via Ste11p MAPKKK: scaffold role of Pbs2p MAPKK. Science 276, 1702-1705. doi: 10.1126/science.276.5319.1702

Ray, L. B., and Sturgill, T. W. (1987). Rapid stimulation by insulin of a serine/threonine kinase in 3T3-L1 adipocytes that phosphorylates microtubuleassociated protein 2 in vitro. Proc. Natl. Acad. Sci. U.S.A. 84, 1502-1506. doi: $10.1073 /$ pnas.84.6.1502

Ray, L. B., and Sturgill, T. W. (1988). Insulin-stimulated microtubule-associated protein kinase is phosphorylated on tyrosine and threonine in vivo. Proc. Natl. Acad. Sci. U.S.A. 85, 3753-3757. doi: 10.1073/pnas.85.11.3753

Rodriguez, M. C., Petersen, M., and Mundy, J. (2010). Mitogen-activated protein kinase signaling in plants. Annu. Rev. Plant Biol. 61, 621-649. doi: 10.1146/ annurev-arplant-042809-112252

Sakiyama, M., and Shibaoka, H. (1990). Effects of abscisic acid on the orientation and cold stability of cortical microtubules in epicotyl cells of the dwarf pea. Protoplasma 157, 165-171. doi: 10.1007/bf01322649

Sakiyama-Sogo, M., and Shibaoka, H. (1993). Gibberellin A3 and abscisic acid cause the reorientation of cortical microtubules in epicotyl cells of the decapitated dwarf pea. Plant Cell Physiol. 34, 431-437.

Sasabe, M., Kosetsu, K., Hidaka, M., Murase, A., and Machida, Y. (2011). Arabidopsis thaliana MAP65-1 and MAP65-2 function redundantly with
MAP65-3/PLEIADE in cytokinesis downstream of MPK4. Plant Signal. Behav. 6, 743-747. doi: 10.4161/psb.6.5.15146

Sasabe, M., Soyano, T., Takahashi, Y., Sonobe, S., Igarashi, H., Itoh, T. J., et al. (2006). Phosphorylation of NtMAP65-1 by a MAP kinase down-regulates its activity of microtubule bundling and stimulates progression of cytokinesis of tobacco cells. Genes Dev. 20, 1004-1014. doi: 10.1101/gad.1408106

Sethi, V., Raghuram, B., Sinha, A. K., and Chattopadhyay, S. (2014). A mitogenactivated protein kinase cascade module, MKK3-MPK6 and MYC2, is involved in blue light-mediated seedling development in Arabidopsis. Plant Cell 26, 3343-3357. doi: 10.1105/tpc.114.128702

Smertenko, A. P., Chang, H. Y., Sonobe, S., Fenyk, S. I., Weingartner, M., Bogre, L., et al. (2006). Control of the AtMAP65-1 interaction with microtubules through the cell cycle. J. Cell Sci. 119(Pt 15), 3227-3237. doi: 10.1242/jcs. 03051

Smyth, D. R., Bowman, J. L., and Meyerowitz, E. M. (1990). Early flower development in Arabidopsis. Plant Cell 2, 755-767. doi: 10.1105/tpc.2.8.755

Soyano, T., Nishihama, R., Morikiyo, K., Ishikawa, M., and Machida, Y. (2003). NQK1/NtMEK1 is a MAPKK that acts in the NPK1 MAPKKK-mediated MAPK cascade and is required for plant cytokinesis. Genes Dev. 17, 1055-1067. doi: 10.1101/gad.107110317/8/1055

Steggerda, S. M., and Paschal, B. M. (2002). Regulation of nuclear import and export by the GTPase Ran. Int. Rev. Cytol. 217, 41-91. doi: 10.1016/S00747696(02)17012-4

Sugden, P. H., and Clerk, A. (1997). Regulation of the ERK subgroup of MAP kinase cascades through G protein-coupled receptors. Cell. Signal. 9, 337-351. doi: 10.1016/S0898-6568(96)00191-X

Sun, S. C., Xiong, B., Lu, S. S., and Sun, Q. Y. (2008). MEK1/2 is a critical regulator of microtubule assembly and spindle organization during rat oocyte meiotic maturation. Mol. Reprod. Dev. 75, 1542-1548. doi: 10.1002/mrd.20891

Sun, Y., Wang, C., Yang, B., Wu, F., Hao, X., Liang, W., et al. (2014). Identification and functional analysis of mitogen-activated protein kinase kinase kinase (MAPKKK) genes in canola (Brassica napus L.). J. Exp. Bot. 65, 2171-2188. doi: 10.1093/jxb/eru092

Takahashi, F., Yoshida, R., Ichimura, K., Mizoguchi, T., Seo, S., Yonezawa, M., et al. (2007). The mitogen-activated protein kinase cascade MKK3-MPK6 is an important part of the jasmonate signal transduction pathway in Arabidopsis. Plant Cell 19, 805-818. doi: 10.1105/tpc.106.046581

Takatani, S., Hirayama, T., Hashimoto, T., Takahashi, T., and Motose, H. (2015). Abscisic acid induces ectopic outgrowth in epidermal cells through cortical microtubule reorganization in Arabidopsis thaliana. Sci. Rep. 5:11364. doi: $10.1038 /$ srep 11364

Teige, M., Scheikl, E., Eulgem, T., Doczi, R., Ichimura, K., Shinozaki, K., et al. (2004). The MKK2 pathway mediates cold and salt stress signaling in Arabidopsis. Mol. Cell 15, 141-152. doi: 10.1016/j.molcel.2004.06.023

Terret, M. E., Lefebvre, C., Djiane, A., Rassinier, P., Moreau, J., Maro, B., et al. (2003). DOC1R: a MAP kinase substrate that control microtubule organization of metaphase II mouse oocytes. Development 130, 5169-5177. doi: 10.1242/dev. 00731

Thitamadee, S., Tuchihara, K., and Hashimoto, T. (2002). Microtubule basis for left-handed helical growth in Arabidopsis. Nature 417, 193-196. doi: 10.1038/ 417193a

Torada, A., Koike, M., Ogawa, T., Takenouchi, Y., Tadamura, K., Wu, J., et al. (2016). A causal gene for seed dormancy on wheat chromosome 4A encodes a MAP kinase kinase. Curr. Biol. 26, 782-787. doi: 10.1016/j.cub.2016. 01.063

Verlhac, M. H., Kubiak, J. Z., Weber, M., Geraud, G., Colledge, W. H., Evans, M. J., et al. (1996). Mos is required for MAP kinase activation and is involved in microtubule organization during meiotic maturation in the mouse. Development 122, 815-822.

Walia, A., Lee, J. S., Wasteneys, G., and Ellis, B. (2009). Arabidopsis mitogenactivated protein kinase MPK18 mediates cortical microtubule functions in plant cells. Plant J. 59, 565-575. doi: 10.1111/j.1365-313X.2009.03895.x

Walter, M., Chaban, C., Schutze, K., Batistic, O., Weckermann, K., Nake, C., et al. (2004). Visualization of protein interactions in living plant cells using bimolecular fluorescence complementation. Plant J. 40, 428-438. doi: 10.1111/ j.1365-313X.2004.02219.x

Wang, H., Ngwenyama, N., Liu, Y., Walker, J. C., and Zhang, S. (2007). Stomatal development and patterning are regulated by environmentally responsive 
mitogen-activated protein kinases in Arabidopsis. Plant Cell 19, 63-73. doi: 10.1105/tpc.106.048298

Weigel, D., and Glazebrook, J. (2002). Arabidopsis : A Laboratory Manual. Cold Spring Harbor, NY: Cold Spring Harbor Laboratory Press.

Yamada, M., and Goshima, G. (2017). Mitotic spindle assembly in land plants: molecules and mechanisms. Biology (Basel) 6, E6. doi: 10.3390/biology601 0006

Yemets, A., Sheremet, Y., Vissenberg, K., Van Orden, J., Verbelen, J. P., and Blume, Y. B. (2008). Effects of tyrosine kinase and phosphatase inhibitors on microtubules in Arabidopsis root cells. Cell Biol. Int. 32, 630-637. doi: 10.1016/ j.cellbi.2008.01.013

Zhang, X., Henriques, R., Lin, S. S., Niu, Q. W., and Chua, N. H. (2006). Agrobacterium-mediated transformation of Arabidopsis thaliana using the floral dip method. Nat. Protoc. 1, 641-646. doi: 10.1038/nprot. 2006.97
Zhao, Y., and Chen, R. H. (2006). Mps1 phosphorylation by MAP kinase is required for kinetochore localization of spindle-checkpoint proteins. Curr. Biol. 16, 1764-1769. doi: 10.1016/j.cub.2006.07.058

Conflict of Interest Statement: The authors declare that the research was conducted in the absence of any commercial or financial relationships that could be construed as a potential conflict of interest.

Copyright $(2017$ Benhamman, Bai, Drory, Loubert-Hudon, Ellis and Matton. This is an open-access article distributed under the terms of the Creative Commons Attribution License (CC BY). The use, distribution or reproduction in other forums is permitted, provided the original author(s) or licensor are credited and that the original publication in this journal is cited, in accordance with accepted academic practice. No use, distribution or reproduction is permitted which does not comply with these terms. 